\title{
A forty-year journey in plant research: original contributions to flavonoid biochemistry
}

\author{
Ragai K. Ibrahim
}

\begin{abstract}
This review highlights original contributions by the author to the field of flavonoid biochemistry during his research career of more than four decades. These include elucidation of novel aspects of some of the common enzymatic reactions involved in the later steps of flavonoid biosynthesis, with emphasis on methyltransferases, glucosyltransferases, sulfotransferases, and an oxoglutarate-dependent dioxygenase, as well as cloning, and inferences about phylogenetic relationships, of the genes encoding some of these enzymes. The three-dimensional structure of a flavonol $O$-methyltransferase was studied through homology-based modeling, using a caffeic acid $O$-methyltransferase as a template, to explain their strict substrate preferences. In addition, the biological significance of enzymatic prenylation of isoflavones, as well as their role as phytoanticipins and inducers of nodulation genes, are emphasized. Finally, the potential application of knowledge about the genes encoding these enzyme reactions is discussed in terms of improving plant productivity and survival, modification of flavonoid profiles, and the search for new compounds with pharmaceutical and (or) nutraceutical value.
\end{abstract}

Key words: flavonoid enzymology, metabolite localization, gene cloning, 3-D structure, phylogeny.

Résumé : Dans cette revue, l'auteur fait état de ses contributions originales à la recherche sur la biochimie des flavonoïdes, au cours des 40 années de sa carrière de recherche. Celles-ci incluent la mise à jour de nouveaux aspects de certaines des réactions enzymatiques impliquées dans les dernières étapes de la biosynthèse des flavonoïdes, avec un accent sur les méthyltransférases, glycotransférases, sulfotransférases et une dioxygénase dépendante de l'oxoglutarate, ainsi que sur le clonage, incluant leurs relations phylogénétiques, des gènes codant pour certaines de ces enzymes. L'auteur a étudié la structure tri-dimensionnelle de la flavonol $O$-méthyltransférase, via une modélisation basée sur l'homologie, en utilisant l' $O$-méthyltransférase de l'acide caféïque comme modèle, afin d'expliquer les préférences strictes de substrat. De plus, il met l'accent sur la signification biologique de la prénylation enzymatique des isoflavones, aussi bien que sur leur rôle comme phytoanticipines et inducteur des gènes de nodulation. Enfin, l'auteur discute de l'application potentielle des connaissances, au sujet des gènes codant pour ces réactions enzymatiques, en termes d'amélioration de la productivité et de la survie des plantes, de la modification des profiles des flavonoïdes, et de la recherche de nouveaux composés utiles en pharmacie et (ou) en nutraceutique.

Mots clés : enzymologie des flavonoïdes, localisation des métabolites, clonage de gènes, structure 3-D, phylogénie.

[Traduit par la Rédaction]

\section{Introduction}

Plants possess an enormous capability to synthesize a large variety of low molecular-weight organic compounds, collectively known as secondary metabolites, which have evolved as a result of their interaction with the surrounding environment. Of these metabolites, flavonoids represent a large family of compounds that are of widespread occurrence throughout the plant kingdom. They exhibit a wide range of functions and play important roles in the biochemistry, physiology, and ecology of plants (Bohm 1998a). They provide pigmentation to flowers, fruits, and seeds, which attracts pollinators and seed dispersers, provide protection against ultraviolet light and pathogen attack, play a

Received 30 November 2004. Published on the NRC Research Press Web site at http://canjbot.nrc.ca on 13 May 2005.

Abbreviations: AdoHcy, $S$-adenosyl-L-homocysteine; AdoMet, $S$-adenosyl-L-methionine; CA, caffeic acid; DMAPP, dimethylallyl pyrophosphate; F6H, flavonol 6-hydroxylase; GT, glucosyltransferase; HCA, hydroxycinnamic acid; 5HF, 5-hydroxyferulic acid; IR, isorhamnetin; K, kaempferol; LCO, lipochitin oligosaccharide; ODD, oxoglutarate-dependent dioxygenase; OMT, $O$ methyltransferase; PAP, 5'-phoshoadenosine 3'-phosphate; PAPS, 5'-phosphoadenosine 3'-phosphosulfate; PT, prenyltransferase; PCR, polymerase chain reaction; Q, quercetin; Qg, quercetagetin; ST, sulfotransferase.

R.K. Ibrahim. Plant Biochemistry Laboratory and Centre for Structural and Functional Genomics, Concordia University, 7141 Sherbrooke Street West, Montréal, QC H4B1R6, Canada (e-mail: ragibra@vax2.concordia.ca). 
Fig. 1. Structures of flavones (A), isoflavones (B), hydrangenol (o, carbon atoms derived from a phenylpropanoid precursor; x, carbon atoms derived from acetate units) (C), and phenylpropanoids (cinnamic acids and coumarin) (D).

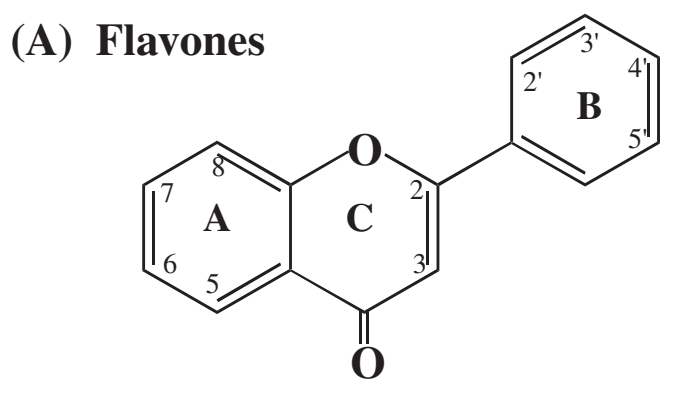

Luteolin

Kaempferol

Quercetin

$5,7,3^{\prime}, 4^{\prime}-\mathrm{OH}$-flavone

Isorhamnetin 3'-OMe-3,5,7,4'-OH

Rhamnetin 7-OMe-3,5,3',4'-OH

Quercetagetin 3,5,6,7,3', $4^{\prime}-\mathrm{OH}$

Patuletin 6-OMe-3,5,7,3',4'-OH

Myricetin 3,5,7,3',4',5'-OH
(B) Isoflavones

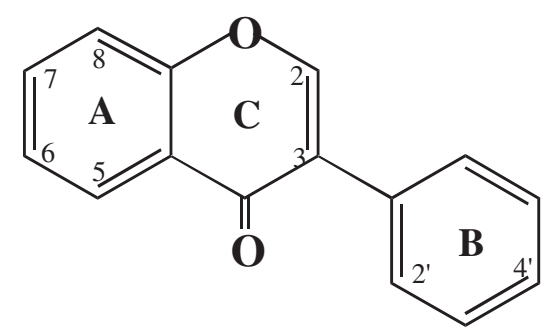

$\begin{array}{ll}\text { Genistein } & \text { 5,7,4'-OH-isoflavone } \\ \text { Wighteone } & \text { 6-Pr-5,7,4'-OH } \\ \text { Lupiwighteone } & \text { 8-Pr-5,7,4'-OH } \\ \text { Luteone } & \text { 6-Pr-5,7,2',4'-OH }\end{array}$

Licoisoflavone A 3'-Pr-5,7,2',4'-OH

Lupalbigenin $\quad 6,3^{\prime}-\mathrm{Pr}-5,7,4^{\prime}-\mathrm{OH}$

\section{(D) Phenylpropanoids}

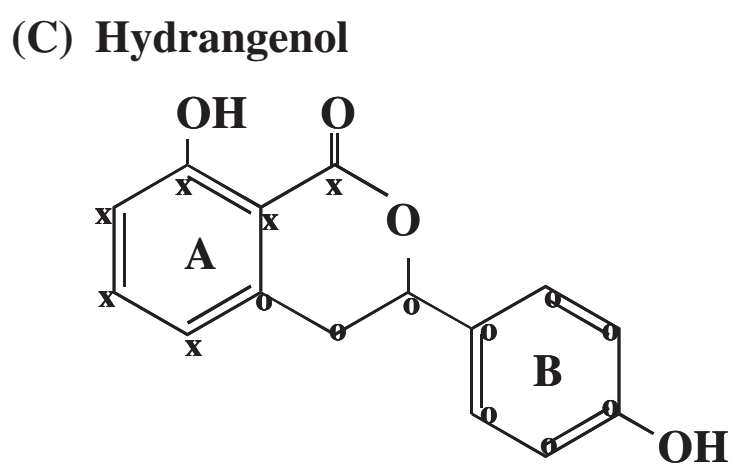

role in pollen germination and plant fertility, and act as signal molecules in plant-microbe interactions (Bohm 1998b). They also provide potential health benefits to humans, acting as nutraceuticals, antioxidants, anti-inflammatory, and as hypolipidemic and anti-cancer agents (Middleton and Kandaswamy 1994; Rice-Evans and Miller 1996; Hollman and Katan 1998; Manthey et al. 2001; Kurowska and Manthey 2004). Such a diverse spectrum of biological activities is probably attributed to the structural diversity associated with a variety of functional group substitutions including hydroxylation, glucosylation, methylation, sulfonation, and prenylation. Since the current state of knowledge of these substitution reactions was published recently (Ibrahim and Anzellotti 2003), only those reports that appeared since will be highlighted here.

Flavonoid compounds consist of two phenyl rings, A and $\mathrm{B}$, that are connected by a three-carbon bridge to form the heterocyclic ring $\mathrm{C}$ (Figs. 1A and B). Rings A and B are derived from the malonate-acetate, and shikimate pathways, respectively. The stepwise condensation of three molecules of malonyl CoA and one molecule of 4-coumaroyl CoA by chalcone synthase results in the formation of a chalcone. The chalcone undergoes a stereospecific cyclization, catalyzed by chalcone isomerase, to the corresponding $(2 S)$ flavanone. The latter metabolite is a branch-point intermediate in the biosynthesis of all other classes of flavonoids, including flavones, isoflavones, flavonols, and anthocyanidins. The enzymes catalyzing the individual steps of flavonoid biosynthesis have been thoroughly reviewed (Forkmann and Heller 1999; Dixon 1999), and the potential roles of their respective genes in the modification of the flavonoid patterns in plants have recently been discussed (Forkmann and Martens 2001; Winkel-Shirley 2001; Schijlen et al. 2004).

To start with, I consider myself privileged to conduct my doctoral studies (1958-1961) with the late Professor Neil Towers, the stalwart of plant biochemistry in Canada, and the 1973 recipient of the Canadian Society of Plant Physiologists Gold Medal. He introduced me to the realm of plant phenolics, a novelty at the time, which "got under my skin" and resulted in a number of original contributions (e.g., 
Ibrahim and Towers 1959, 1960a, 1960b, 1961, 1962; Ibrahim et al. 1961, 1962a, 1962b; Ibrahim 1964) that impacted the field of phenolic biosynthesis at the time. One of these (Ibrahim and Towers 1960a) described, for the first time, a paper chromatographic method for the separation and identification of plant phenolic acids that became the hallmark during the 1960s and served as a foundation for numerous surveys of these compounds by many plant scientists. However, the major part of my doctoral research dealt with the biosynthesis of a novel phenylisocoumarin, hydrangenol (Fig. 1C), formed from an intact phenylpropanoid precursor (ring B) and three acetate units (ring A), as is the case with flavonoids, except for $\mathrm{C} 1$ of the phenylpropanoid precursor, which forms a part of a branched A-ring in hydrangenol.

I was also privileged to spend a sabbatical year with the late Professor Hans Grisebach in Freiburg, Germany (19741975), where I had my first serious encounter with phenolic enzymology (Ibrahim and Grisebach 1976; Ibrahim 1977).

My journey in plant biochemistry research started in earnest with the phytochemical investigation of a tiny saxifragaceous semi-aquatic weed, Chrysosplenium americanum Schwein., which accumulates a variety of highly methylated flavonol glucosides, but none of the less methylated intermediates (Collins et al. 1981). This plant material was the "treasure chest" of the laboratory, as the source of many novel enzymes, present in very low abundance, that created enormous challenge for the determination of their ordained sequence in the biosynthetic pathway of these exotic metabolites. In spite of its limited distribution and a requirement for a cool temperature and a high relative humidity, $C$. americanum has allowed us to characterize a number of novel enzymes at the biochemical level, to clone some of their genes, and to study the compartmentalization of such rare metabolites. The enzyme complement involved in the biosynthesis of these flavonol glucosides includes five $O$ methyltransferases, two glucosyltransferases, one oxoglutaratedependent dioxygenase, and one, as yet unexplored, monooxygenase.

Another hallmark of this journey involves our original work on flavonoid sulfonation. Research into the phytochemistry of sulfated flavonoids began around the 1930s (for review, see Barron et al. 1988); however, there has been a conspicuous lack of knowledge about the enzymatic synthesis, mainly because of the lack of a reliable enzyme assay for sulfotransferases and the unavailability of the pertinent reference compounds. Two Flaveria spp., F. bidentis (L.) Kuntze and $F$. chloraefolia (Asteraceae), enabled the characterization of the sulfotransferases involved in the biosynthesis of flavonol tetrasulfate, the major metabolite that accumulates in F. bidentis, and the cloning of cDNAs encoding two key enzymes.

The following is a brief review of the highlights of these contributions.

\section{Enzymatic O-methylation of phenolics and flavonoids}

$O$-Methylation is catalyzed by a family of $S$-adenosyl-Lmethionine (AdoMet)-dependent $O$-methyltransferases (OMTs). They catalyze the transfer of the methyl group of AdoMet to specific hydroxyls of an acceptor molecule with the concomitant formation of the corresponding methyl ether derivative and $S$-adenosyl-L-homocysteine (AdoHcy) as products. $O$-Methylation of flavonoids confers a variety of biological functions such as signaling molecules in Rhizobium-legume symbiotic interactions, antiviral agents, and the reduction of flavonoid mutagenicity in animals (Zhu et al. 1994).

Recent advances in protein separation techniques and the characterization of cloned OMT gene products (Ibrahim and Muzac 2000) indicate that OMTs are both substrate-specific and position-oriented enzymes. The following is a review of our earlier investigations that led to the more challenging aspects of methyltransferases.

\section{$\boldsymbol{O}$-Methylation of hydroxycinnamic acids}

The methylation of hydroxycinnamic acids (HCA) is an important enzymatic reaction in the biosynthesis of lignin in all vascular plants. HCA OMTs catalyze the differential 3methylation of caffeic acid (CA) and 5-methylation of 5hydroxyferulic acid $(5 \mathrm{HF})$ to produce ferulic and sinapic acids (Fig. 1D), the precursors of the monolignols, and coniferyl and sinapyl alcohols, respectively. It was commonly believed that the methylation of both acids is catalyzed by one bifunctional and bispecific OMT. However, we purified, for the first time, HCA-OMT isoforms I and II to near homogeneity from young cabbage leaves. Isoform I exhibits a sinapic acid to ferulic acid ratio of about 1.7-1.8, whereas isoform II has a ratio of 2.6-2.8. These product ratios are consistent during enzyme purification on DEAEcellulose, hydroxyapatite, and chromatofocusing, indicating distinct substrate preferences for the two isoforms (De Carolis and Ibrahim 1989). Since cabbage leaves accumulate a variety of sinapoyl esters as the major phenylpropanoid compounds, it is reasonable to assume that the differential activity of the isoforms reflects two distinct enzymes whose encoding genes await to be cloned and characterized. This situation is similar to the flavonoid $3^{\prime}-$ and $3^{\prime}-/ 5^{\prime}-$ hydroxylases in Petunia hybrida which are, in fact, two distinct enzymes encoded by genes assigned to the loci $H f l$ and Hf2, respectively, (Holton and Cornish 1995).

We also presented the first evidence for the existence of two distinct, substrate-specific OMTs in tobacco cell cultures (Tsang and Ibrahim 1979). One OMT, a meta-directing enzyme catalyzes the methylation of caffeic acid (a phenylpropanoid) to ferulic acid, whereas the second, a para-directing form methylates quercetin (a flavonol) to its 7-methyl derivative, rhamnetin (Fig. 1A). In spite of the similarities between the two enzyme forms in $M_{\mathrm{r}}(70-74 \mathrm{kDa})$ and $\mathrm{pI}$ values, differences in $\mathrm{pH}$ optima, inhibition by $\mathrm{SH}$ group reagents, and ratios of $m / p$-methylation, as well as evidence obtained from mixed substrate experiments, indicate their distinct nature. This demonstrated that methylation of the structurally related phenylpropanoid and flavonoid compounds is catalyzed by distinct enzymes.

$O$-Methylation of hydroxycoumarins is a common enzymatic reaction that contributes to their diverse biological activities. A well-known example is the 6-O-methylation of esculetin (6,7-dihydroxycoumarin) to scopoletin, an antifungal metabolite that accumulates in potato tubers. Recently, we isolated and characterized a gene encoding a 
novel OMT that catalyzes the specific methylation of 7,8dihydroxycoumarin (daphnetin, Fig. 1D) at the 8-position, but not of its isomer, esculetin (N'Dong et al. 2003). This gene is associated with the development of freezing tolerance in winter cereals. Daphnetin has been reported to be a protein kinase inhibitor (Yang et al. 1999), suggesting that its methylation may be involved in low temperature signaling that is known to be regulated by protein kinases and phosphatases.

\section{$O$-Methylation of flavonoids}

We demonstrated the stepwise methylation of flavonols by partially purified protein extracts of calamondin orange peel (Brunet and Ibrahim 1980), apple fruit cell cultures (Macheix and Ibrahim 1984), and spinach leaves (Thresh and Ibrahim 1985). In all these systems, stepwise methylation proceeds from the parent flavonol, quercetin $(\mathrm{Q})$ $\rightarrow 3-\mathrm{MeQ} \rightarrow 3,7$-diMeQ $\rightarrow 3,7,4^{\prime}$-triMeQ (Fig. 1A), following a decreasing order of the negative electron densities of the 3-, 7-, and 4'-hydroxyl groups (Pople and Beveridge 1970).

Lotus corniculatus L. represents an interesting example of the ontogeny of flavonols in different organs of the plant. The leaves contain kaempferol (K), quercetin (Q), and isorhamnetin (IR), whereas the flowers accumulate the two latter compounds, as well as their 8-substituted derivatives, 8-OMeK, 8-OMeQ, and 8-OMeIR (Fig. 1A). We also demonstrated, for the first time, that meta-methylation of ring A (position 8) and ring $\mathrm{B}$ (position $3^{\prime}$ ) is catalyzed by two distinct OMTs with $\mathrm{pH}$ optima of 8.1 and 7.7, pI values of 5.5 and 5.1, and absolute and no requirement of SH groups for enzyme activity, respectively, (Jay et al. 1982). In fact, both enzymes represent another level (rings $\mathrm{A} / \mathrm{B}$ ) of stereospecificity. However, it is interesting to note that the young flower buds exhibit the highest 8-OMT activities with all of the three flavonol substrates, whose products contribute to the characteristic yellow colour of Lotus flowers (Jay et al. 1982).

A novel flavonol 8-OMT was highly purified from Lotus flower buds by ammonium sulfate precipitation and successive chromatography on Sephadex G-100, hydroxyapatite, and AdoHcy-Agarose affinity columns, with a 1200 -fold increase in specific activity. This enzyme requires $\mathrm{Mg}^{2+}$ and SH groups for activity, and exhibits a strict specificity for position 8 of 8-OHK and 8-OHQ with a $\mathrm{pH}$ optimum of 7.9, a pI value of 5.5 , and an $M_{\mathrm{r}}$ of $55 \mathrm{kDa}$. The $K_{\mathrm{m}}$ values for 8OHK and AdoMet are 1.3 and $53 \mu \mathrm{mol} / \mathrm{L}$, respectively, and the enzyme displays an ordered bi-bi reaction mechanism, with 8-OH-flavonol binding before AdoMet, and release of AdoHcy before the methylated product (Jay et al. 1985).

We also showed that methylation of position 5 of the isoflavone genistein (Fig. 1B) is catalyzed by a positionspecific OMT in yellow lupin roots (Khouri et al. 1988a). 5$O$-Methylation of flavonoids is considered rare because of chelation of its least reactive 5-OH group with the carbonyl group of the heterocyclic ring. However, 5-O-methylation of isoflavones may be attributed to the specific binding of the flavonoid substrate and cosubstrate, in a geometrical arrangement relative to each other, such that methylation at position 5 is preferentially catalyzed.

\section{The polymethylated flavonol glucosides of C. americanum}

Chrysosplenium americanum shoots accumulate six, tetrato penta- $O$-methylated flavonol glucosides (Collins et al. 1981). Two of these glucosides (A and B) are derived from 2'-hydroxy quercetin $(\mathrm{Q})$, two others (C and D) are 6hydroxyquercetin (quercetagetin $(\mathrm{Qg})$ ) derivatives and the remaining two (E and F) are 6,2'-disubstituted metabolites (Fig. 2). The first pair of compounds is glucosylated at the less common 2'-position, whereas all the others are 5'-Oglucosides. However, none of the partially methylated aglycones accumulate in this tissue, although they can be synthesized enzymatically in vitro. In fact, tracer experiments using $\left[2-{ }^{14} \mathrm{C}\right]$ cinnamate result in labeling of the six flavonoid glucosides within a 5-min pulse, with little if any label residing in the early methylated intermediates, suggesting efficient channeling of the substrates and intermediates towards the final products. Furthermore, partially purified enzyme preparations catalyze the methylation of quercetin to its 3-mono-, 3,7-di- and 3,7,4'-trimethyl derivatives (De Luca and Ibrahim 1982), as well as the glucosylation of triand tetra-methylated intermediates to their corresponding glucosides (Bajaj et al. 1983). This indicates the existence of the entire complement of enzymes involved in the biosynthesis of polymethylated flavonol glucosides in this plant.

\section{The sequence of enzymatic methyl transfer reactions in C. americanum}

The six enzymes involved in the sequential methylation were purified 400 - to 650 -fold. They exhibit strict substrate and position specificities for positions 3 of the parent aglycone quercetin (3-OMT), 7 of 3-MeQ (7-OMT), 4' of 3,7-diMeQ (4'-OMT), and 6 of 3,7,4'-triMeQ (6-OMT). In contrast with the four early enzymes in the pathway, which accept only aglycones as substrates (De Luca and Ibrahim 1985a; Khouri et al. 1988b), further methylation at the 2'and $5^{\prime}$-positions takes place at the glucoside level by a $2^{\prime}-15^{\prime}-$ OMT (Fig. 2). The latter enzyme utilizes 5,2',5'trihydroxy$3,7,4^{\prime}$-trimethoxy-flavone $2^{\prime}$-glucoside and $5,2^{\prime}, 5^{\prime}$-trihydroxy$3,6,7,4^{\prime}$-tetramethoxyflavone $5^{\prime}$-glucoside as substrates for methylation at the $5^{\prime}$ - and $2^{\prime}$-positions, respectively (Khouri et al. 1986). However, in view of the strict position specificity of earlier enzymes, it can be assumed that the two later methylation steps are mediated by two distinct OMTs, which remain to be resolved, as in the case of the $2^{\prime}-15^{\prime}-O$ glucosylations (see below). These OMTs have similar physicochemical properties, except for the $\mathrm{Mg}^{2+}$ requirement of the 6-OMT for activity, and the distinct difference in their pI values, which allows their separation by chromatofocusing (Fig. 2, inset) (Khouri and Ibrahim 1987).

These enzymatic steps indicate an ordained sequence of methyl transfers from AdoMet to quercetin to give rise to 3$\mathrm{MeQ} \rightarrow$ 3,7-diMeQ $\rightarrow$ 3,7,4'-triMeQ, a branch point intermediate (Fig. 2). After hydroxylation of the latter at the 2 -position and its subsequent glucosylation (compound A), it is further methylated to its $5^{\prime}$-methyl derivatives (compound B). Hydroxylation of 3,7,4'-triMeQ at position 6 , followed by methylation at the same position and glucosylation at position $5^{\prime}$ give rise to compounds $\mathrm{C}$ and D. Further 2'- 
Fig. 2. A proposed pathway for the enzymatic synthesis of polymethylated flavonol glucosides in Chrysosplenium americanum, showing the end metabolites $(\mathrm{A}-\mathrm{F})$ that accumulate in the leaves and the enzymes involved in their biosynthesis. GT, $O$-glucosyltransferase; OHase, hydroxylase; OMT, $O$-methyltransferase; numbers preceding these enzymes refer to the positions they attack. Inset: Fast protein liquid chromatographic separation profile of the OMTs involved in polymethylated flavonol synthesis using a mono-P chromatofocusing column.

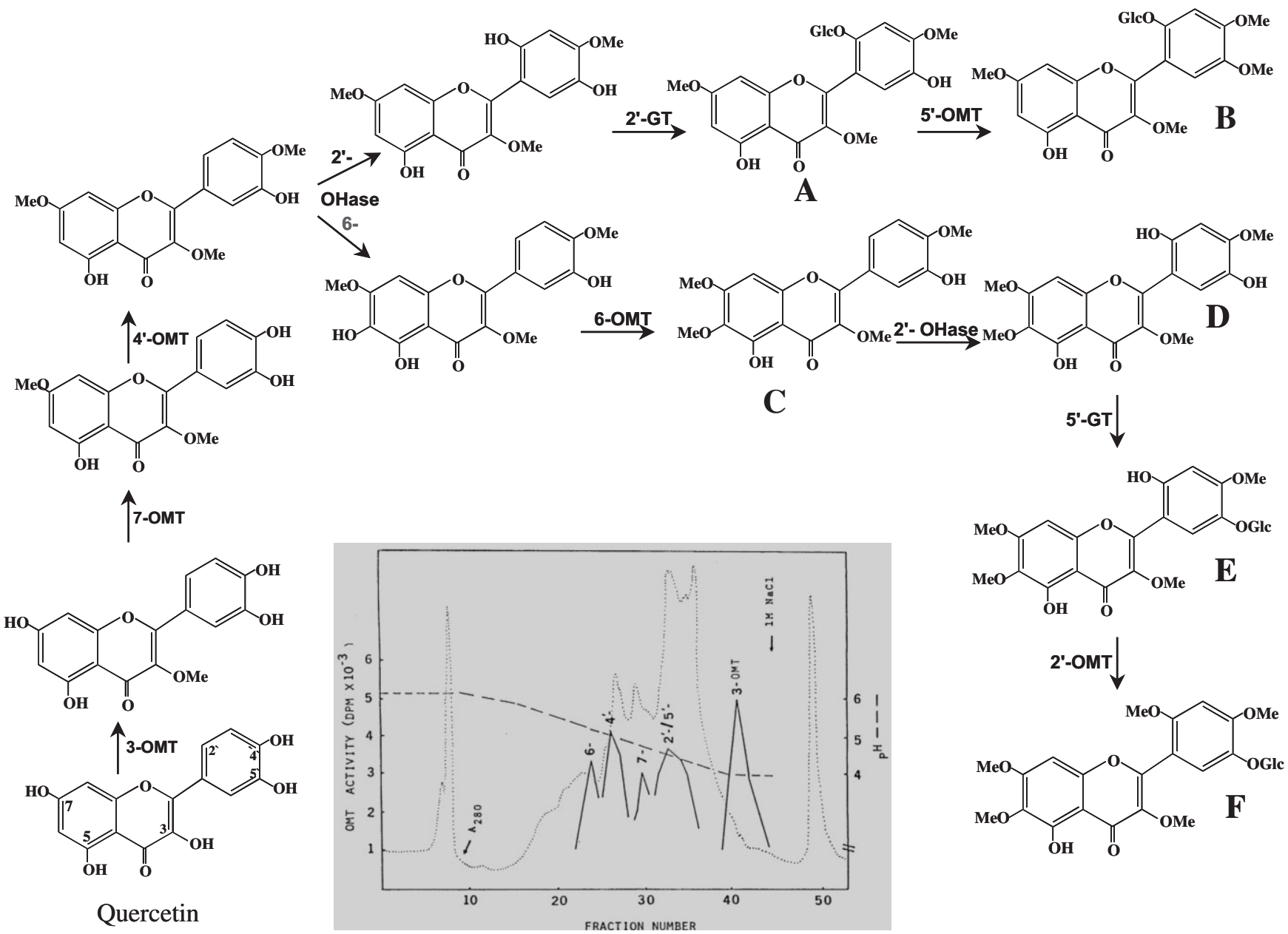

hydroxylation of compound $\mathrm{C}$, followed by $2^{\prime}$-methylation and $5^{\prime}$-glucosylation give rise to compounds $\mathrm{E}$ and $\mathrm{F}$.

Kinetic analysis of Chrysosplenium OMTs (De Luca and Ibrahim 1985b; Khouri et al. 1988b) indicate a tendency, along the methylation sequence, towards decreasing $K_{\mathrm{m}}$ values for the flavonoid substrates and increasing $K_{\mathrm{i}}$ values for the methylated products, in addition to the low $K_{\mathrm{i}}$ values for AdoHcy. These features are typical for a channeled pathway and further suggest that earlier enzymes in the pathway may regulate the synthesis and accumulation of the final products.

\section{Enzymatic glucosylation of methylated flavonols in C. americanum}

The major flavonoids of $C$. americanum are distinguished by their glucosylation at the less common positions $2^{\prime}$ and $5^{\prime}$ of the flavonol ring system (Fig. 2). Both the 2'- and 5'glucosyltransferase (GT) activities usually eluted within the same fractions from a number of conventional chromatographic columns, suggesting a single enzyme protein catalyzing both GT activities (Bajaj et al. 1983). However, this activity was later resolved into two distinct $2^{\prime}$ - and 5'-GTs by successive affinity chromatography on UDP-glucuronic acid agarose, followed by Brown 10 Dye ligand, columns. The protein fractions with GT activity were eluted from the latter column using a linear $\mathrm{pH}$-salt gradient at $\mathrm{pH}$ values of 7.8 and 7.3, respectively (Latchinian et al. 1987). That each of the purified proteins gives a single product, when assayed against its respective substrate, indicates the position specificity of both enzymes. Both the $2^{\prime}-$ and $5^{\prime}$-GTs exhibit similar physicochemical and kinetic properties. The high $K_{\mathrm{i}}$ value $(1 \mathrm{mmol} / \mathrm{L})$ for the glucosylated products indicates that glucosylation of flavonoids is not inhibited by the products formed and is consistent with their accumulation in this tissue (Khouri and Ibrahim 1984).

Further evidence for the existence of two distinct enzymes was obtained from immunological studies. A murine monoclonal antibody to the partially purified GT was produced in vitro using Balb/c mice spleen cells, followed by fusion with mouse myeloma cells. A highly immunoreactive IgM-secreting clone displays $>50 \%$ inhibition of the $2^{\prime}-\mathrm{GT}$, but not the $5^{\prime}-\mathrm{GT}$, activity. Moreover, the native form of the enzyme is essential for antibody recognition on Western blot analysis (Latchinian and Ibrahim 1989). 
The above account indicates that the enzymatic synthesis of polymethylated flavonol glucosides in $C$. americanum is regulated by strict substrate and position specificities of the enzymes involved, their ordained sequence in the pathway, and some kinetic considerations. This suggests that the multienzyme system for flavonoid biosynthesis in this species is highly organized as a linear sequence of enzymes that not only prevents accumulation of the early methylated intermediates but also permits effective channeling of the substrates and products, and facilitates packaging and transport of the final metabolites (Ibrahim 1992).

\section{Hydroxylation of 3,7,4'-trimethylquercetin at the 6- and $2^{\prime}$-positions}

In the course of biosynthesis of Chrysosplenium flavonoids, the partially methylated intermediate $3,7,4^{\prime}$ trimethylquercetin undergoes either of two hydroxylation steps at positions 6 or $2^{\prime}$ to give rise to the $2^{\prime}$ - mono- or $6,2^{\prime}$ disubstituted metabolites (Fig. 2). Whereas the 2'hydroxylation seems to be catalyzed by a membraneassociated, cytochrome P450-dependent monooxygenase (D. Werck-Reichhart, personal communication, 2002), hydroxylation at position 6 is mediated by a novel, soluble 2-oxoglutarate-dependent dioxygenase.

The latter enzyme, flavonol 6-hydroxylase (F6H), was purified to near homogeneity by fast protein liquid chromatography (FPLC) on superose 12 and mono Q columns, as well as by affinity chromatography on 2-oxoglutarate-sepharose and immunoaffinity columns (Anzellotti and Ibrahim 2000). The 42- to $45-\mathrm{kDa}$ protein exhibits strict specificity to position 6 of partially methylated flavonols, as shown by a coupled enzyme assay with the 6-OMT, indicating its involvement in the biosynthesis of polymethylated flavonoids in this plant (Fig. 2). The cofactor dependence of the enzyme (2-oxoglutarate, $\mathrm{Fe}^{2+}$, and ascorbate) is similar to that of other plant oxoglutarate-dependent dioxygenases (ODDs). Internal amino acid sequence information indicate its relation to other plant flavonoid dioxygenases. Kinetic analysis suggests an ordered, sequential ter-ter reaction mechanism, whereby 2-oxoglutarate is the first substrate to bind, followed by oxygen and then the flavonol substrate. Product release occurs in the reverse order, where the hydroxylated flavonol is the first to be released, followed by $\mathrm{CO}_{2}$ and succinate. This is the first reported 2-oxoglutarate-dependent dioxygenase that catalyzes the aromatic hydroxylation of a flavonoid compound (Anzellotti and Ibrahim 2000).

\section{Localization of Chrysosplenium flavonoids}

Although flavonoids in $C$. americanum are mostly lipophilic because of the presence of 4 to 5 methoxyl groups, they are also partly hydrophilic because of the presence of glucosyl residues. It is not unexpected, therefore, that these compounds are secreted on the external leaf surface. This dual solubility property prompted us to use three different approaches to study their localization in situ.

Histochemical studies, using caffeine as a prefixative and a staining reagent for electron microscopy, revealed that the walls of leaf epidermal and mesophyll cells are impregnated with electron-dense deposits, as well as various membrane profiles and associated vesicles, indicative of the site of flavonoid accumulation. However, the Golgi bodies did not acquire the caffeine stain, suggesting that they are not involved in flavonoid secretion. Moreover, these cell wall deposits could be leached out by dipping the leaves in acetone for 1- to 2-s intervals. HPLC analysis of these effusates indicated the recovery of the major flavonoid glucosides of this tissue (Charest et al. 1986).

Immunolocalization of flavonoids was conducted using a polyclonal antibody raised in rabbits against compound $\mathrm{A}$, although the antibody also cross-reacted with compounds B and F (Fig. 2), but not against the parent aglycone, quercetin (Lamoureux et al. 1986). The use of an indirect immunofluorescence technique and fluorescin isothiocyanate (FITC)-labeled goat anti-rabbit antibody with isolated leaf epidermal layers, frozen leaf sections and isolated mesophyll protoplasts, indicated a specific immunofluorescence labeling of flavonoids, as compared with the non-immune serum, in the walls of epidermal and mesophyll cells, but not in the cellular vacuoles (Brisson et al. 1986).

Further evidence for the site of flavonoid accumulation was obtained using the protein A-gold postembedding technique and the anti-compound $\mathrm{A}$ antibody on thin sections with the aid of transmission electron mictoscopy. Antibodyspecific labeling was associated with epidermal cell walls and plasmalemma, but not with such organelles as ER membranes, Golgi bodies, or chloroplasts (Marchand et al. 1987). Furthermore, immunogold localization of the GTs involved in the polymethylated flavonol glucoside synthesis indicated that the gold label is associated with vesicle-like structures and cytoplasmic membranes of the epidermal cells (Latchinian and Ibrahim 1991). These observations corroborate well with those obtained from both the histochemical and immunocytochemical studies and provide strong evidence for the cell wall localization of Chrysosplenium flavonoids, although the nature of their association with the cell wall components remains to be determined.

\section{Model for compartmentalization of Chrysosplenium flavonoids}

The enzymatic synthesis of polymethylated flavonol glucosides in $C$. americaum is catalyzed by 10 substratespecific and position-oriented enzymes. These consist of six OMTs, two hydroxylases, and two GTs (Fig. 2). The ordered, channeled nature of these enzymes (Ibrahim et al. 1987; Ibrahim 1992), as well as the immunolocalization of the glucosyltransferases (Latchinian and Ibrahim 1991) and final metabolites (Charest et al. 1986; Marchand et al. 1987), strongly suggest that the ER membrane is the location of such an elaborate multienzyme system (Chrispeels 1980; Stafford 1990). This model of compartmentalization assumes a linear sequence of the early enzymes involved in quercetin methylation, the 3-, 6-, 7-, and 4'-OMTs along the cytoplasmic side of the ER membrane. The resulting 3,7,4'triMeQ is a branch-point intermediate for two alternative pathways. In one pathway, this intermediate is hydroxylated at the $2^{\prime}$-position, possibly by a membrane embedded, cytochrome P450 monooxygenase, then glucosylated at that position, before further methylation at position $5^{\prime}$ to give rise to $3,7,4^{\prime}, 5^{\prime}$-tetramethoxy flavone- $2^{\prime}$-glucoside. The second pathway involves 6-hydroxylation of the partially methylated intermediate, by a soluble flavonol 6-hydroxylase, followed by methylation of that hydroxyl, then glucosylation at the $5^{\prime}$ - 
position, and a final methylation at the 2 -position to give rise to $3,6,7,2^{\prime}, 4^{\prime}$-pentamethoxyflavone-5'-glucoside (Fig. 2). It is assumed that glucosylation at the $2^{\prime}$ - and $5^{\prime}$-positions and further methylation of their respective products at the $5^{\prime}$ and 2 -positions take place on the other (lumen) side of the membrane in a more hydrophilic environment. Metabolite accumulation would result in the swelling of certain regions of the membrane with the formation of membrane vesicles, which eventually move towards, and fuse with the plasmalemma at the cell surface releasing their flavonoid content within (or outside) the cell wall by exocytosis (Chrispeels 1980). The evidence obtained from electron microscopic studies revealing the presence of electron-dense deposits, metabolite- and glucosyltransferse-specific antibody labeling in cell walls, membrane profiles, and associated vesicles support this working model of flavonoid ompartmentation in $C$. americanum.

\section{Serratula tinctoria flavonol 3-O-mehyltransferase}

In contrast with Chrysosplenium, which contains six OMTs with similar properties, both shoots and roots of Serratula tinctoria L. (Asteraceae) accumulate mainly 3,3'dimethylquercetin (3,3'-diMeQ) and small amounts of 3methylquercetin (3MeQ) as an intermediate (Fig. 1A), suggesting the existence in these tissues of a Q 3-OMT and a 3-MeQ 3'-OMT, in addition to the lignin monomer OMT. 3-Methylated flavonols rarely accumulate in plants, since they serve as intermediates in the biosynthesis of partially methylated flavonoids. 3-O-Methylation of quercetin confers some distinct properties to this rare metabolite. In addition to being an anti-inflammatory and antiviral agent, 3-MeQ has recently been reported to accumulate in tobacco leaf trichomes, together with other methylated flavonols, in response to wounding stress and herbivory (Roda et al. 2003). These characteristics prompted the purification of the Q 3OMT, since methylation at position 3 constitutes the first committed step in the sequence of multiple methylations.

The flavonol 3-OMT was highly purified from S. tinctoria leaves by ammonium sulfate precipitation and successive chromatography on superose 12 , mono Q, and adenosineagarose affinity columns, resulting in 194-fold increase of its specific activity (Huang et al. 2004). The 3-OMT ( $M_{\mathrm{r}}$ of ca. $31 \mathrm{kDa})$ was successfully separated from the 3-MeQ $3^{\prime}-$ OMT $\left(M_{\mathrm{r}}\right.$ of ca. $\left.39 \mathrm{kDa}\right)$ and the lignin monomer OMT $\left(M_{\mathrm{r}}\right.$ of ca. $42 \mathrm{kDa}$ ) activities, all of which were immunorecognized by an anti-flavonol 3'-OMT antibody (Séguin et al. 1998). The enzyme exhibits highest activity with quercetin and also utilizes kaempferol and myricetin, as well as some B-ring monomethyl quercetin derivatives as substrates (Fig. 1A); however, there is no activity with the flavanones, flavones, or isoflavones tested, indicating its specificity for flavonols. It has a pH optimum of 7.6 and a $\mathrm{pI}$ of 6.0, and does not accept caffeoyl CoA as a substrate, suggesting that it is a distinct member of group II OMTs, in spite of its low $M_{\mathrm{r}}$. It has no requirement for $\mathrm{Mg}^{2+}$ but is severely inhibited by $\mathrm{SH}$-group reagents. Its respective $K_{\mathrm{m}}$ values for the substrate $\mathrm{Q}$ and the cosubstrate AdoMet are 12 and $45 \mu \mathrm{mol} / \mathrm{L}$. Quercetin methylation is competitively inhibited by AdoHcy with respect to the cosubstrate AdoMet and follows a sequential bi-bi reaction mechanism. In-gel trypsin digestion of the SDS-PAGE-purified 3-OMT yielded several peptides, two of which exhibit strong amino sequence homology to a number of previously identified group II OMTs (Ibrahim et al. 1998). The peptide sequence information will allow cloning of the gene encoding this novel enzyme (Huang et al. 2004).

\section{Enzymatic sulfonation of flavonoids}

Sulfated flavonoids are ubiquitous in plants. Most of these compounds are sulfate esters of common hydroxyflavones and hydroxyflavonols, or their methyl ethers and, less commonly, of their glycosylated derivatives (for review, see Barron et al. 1988). In contrast with the known physiological roles of sulfated conjugates (phenols, steroids, bile acids, xenobiotics) in animal tissues, the functional significance of flavonoid sulfates in plants is not clear. Apart from their involvement in the detoxification of reactive hydroxyl groups, their accumulation in plants growing in saline or marshy habitats suggests a possible role in sequestering sulfate ions. However, investigation of the differential distribution of flavonol sulfates and sulfotransferase (ST) activity in tissues of $F$. bidentis (Hannoufa et al. 1991), and the effect of flavonol aglycones and their sulfate esters on ST activity in F. bidentis cell cultures (Ananvoranich et al. 1994) suggest a role for sulfated flavonols in an interactive mechanism for auxin transport, especially in species that accumulate such metabolites.

Significant advances occurred in the phytochemistry (Barron and Ibrahim 1986, 1987a, 1987b; Barron et al. 1986, 1988d), organic synthesis (Barron and Ibrahim 1987c, $1988 a, 1988 b)$, chemical detection, and spectroscopic analysis (Barron and Ibrahim 1988c) of flavonoid sulfates in the 1980s. To pursue our interest in the enzymology of these compounds, we developed a reliable ST assay (Varin et al. 1987a) and acquired a synthetic depository of sulfated compounds for use as enzyme substrates and reference compounds (Barron and Ibrahim 1987c, 1988a, 1988b). In fact, our current knowledge of sulfated flavonoid phytochemistry, enzymology, and molecular biology is based on the pioneering efforts and original works of Denis Barron and Luc Varin during the period 1985-1992.

\section{Stepwise sulfonation of flavonol tetrasulfate in Flaveria spp.}

Preliminary investigation of the biosynthesis of sulfated and glucosylated flavonols in $F$. bidentis (Asteraceae) from $\left[{ }^{3} \mathrm{H}\right]$ cinnamate and $\left[{ }^{35} \mathrm{~S}\right]$ sulfate indicated that the former label is predominantly incorporated into flavonoid glucosides, whereas the latter is incorporated into sulfate esters. These results reveal that enzymatic sulfonation is a later step in flavonoid biosynthesis, and the nature of substrates to be used for the isolation and characterization of plant STs (Varin et al. 1986).

Flavonoid sulfonation is a conjugation reaction catalyzed by a small family of soluble STs that utilize 3'phosphoadenosine $5^{\prime}$-phosphosulfate (PAPS) as the sulfate donor (Ibrahim and Varin 1993). However, both PAPS and the sulfated reaction product are soluble in aqueous media, making it difficult to separate them by conventional solvent partitioning. Therefore, a novel enzyme assay was developed, which utilizes an ion-pairing reagent, tetrabuty- 
lammonium dihydrogen phosphate, to render the enzyme reaction product soluble in organic solvents, without influencing the solubility of PAPS in the aqueous reaction mixture, thereby eliminating the need to use HPLC for their separation (Varin et al. 1987a). This enabled the first demonstration of ST enzyme activity in cell-free extracts of $F$. bidentis and $F$. chloraefolia, and the existence of a small family of enzymes involved in the biosynthesis of polysulfated flavonols (Varin et al. 1987b).

Four position-specific flavonol STs were isolated and characterized from $F$. chloraefolia (Varin and Ibrahim 1989) and F. bidentis (Varin and Ibrahim 1991). The sequential order of enzymatic sulfonation of flavonol tetrasulfate was envisaged to begin with the sulfonation of quercetin at position 3 by the 3-ST, followed by sulfonation at position $3^{\prime}$ (in F. bidentis) or 4' (in F. chloraefolia) by a $3^{\prime} / 4^{\prime}-\mathrm{ST}$, and then at position 7 of the 3,3'- or 3,4'-disulfates by a 7-ST to give rise to flavonol $3,7,3^{\prime}-$ or $3,7,4^{\prime}$-trisulfates. Finally, a flavonol $3^{\prime} / 4^{\prime}-\mathrm{ST}$ acts on either of the trisulfates to give rise to Q3,7,3', $4^{\prime}$-tetrasulfate (Fig. 3), the major sulfated compound that accumulates in F. bidentis. Q-3,7-disulfate accumulation in significant amounts in both species implies the step wise action of an aryl sulfatase on the tetrasulfate to the disulfate derivative (Varin 1992).

The flavonol 3-ST was further purified to near homogeneity (Varin and Ibrahim 1992) for future cloning of its gene. These enzymes possess similar physicochemical properties and can only be separated by affinity chromatography of the ammonium sulfate pellet on a $3^{\prime}$-phosphoadenosine $5^{\prime}$-phosphate (PAP)-agarose column, followed by chromatofocusing, where they exhibit distinct pI values between 5.1 and 6.5. Their $K_{\mathrm{m}}$ values for the sulfate donor and the flavonol acceptors are in the micromolar range, indicating high affinity for their substrates and tight regulation of flavonol sulfate biosynthesis. Substrate interaction kinetics of the flavonol 3ST resulted in converging patterns that are consistent with a sequential bi-bi reaction mechanism. Product inhibition studies revealed competitive inhibition between PAPS and PAP, and non-competitive patterns between the flavonol substrate and either of the reaction products (Varin and Ibrahim 1992).

It is interesting to note the correlation among five Flaveria species belonging to photosynthetic types and the profile of their sulfated flavonol aglycones involved in their conjugation, and ST enzyme activities. These include Flaveria trinerva (Spreng.) C. Mohr $\left(\mathrm{C}_{4}\right), F$. bidentis $\left(\mathrm{C}_{4^{-}}\right.$ like), $F$. chloraefolia, Flaveria floridana JR Johnston, and Flaveria linearis Lag. (all $\mathrm{C}_{3}-\mathrm{C}_{4}$ ), and Flaveria pringlei Gandoger. $\left(\mathrm{C}_{3}\right)$. It appears that both the $\mathrm{C}_{4}$ and $\mathrm{C}_{4}$-like species exhibit the highest ST activities, accumulate highly sulfated (mono- to tetra-sulfates) compounds, mostly of isorhamnetin (3'-MeQ) and quercetin/kaempferol, as compared with the $\mathrm{C}_{3}$ and $\mathrm{C}_{3}-\mathrm{C}_{4}$ species, which accumulate flavonoids of lower sulfation level that are based on quercetin and its 6-methoxy derivative, patuletin (Hannoufa et al. 1994). Further investigation of other Flaveria species should reveal the physiological significance of these observations, allowing for the construction of a phylogeny of these species with the aim of evaluating their evolutionary significance.
Fig. 3. A proposed pathway for the enzymatic synthesis of sulfated flavonols in Flaveria bidentis and Flaveria chloraefolia. ST, sulfotansferase; numbers preceding STs refer to the positions they sulfonate.<smiles>O=c1c(O)c(-c2ccc(O)c(O)c2)oc2cc(O)cc(O)c12</smiles>

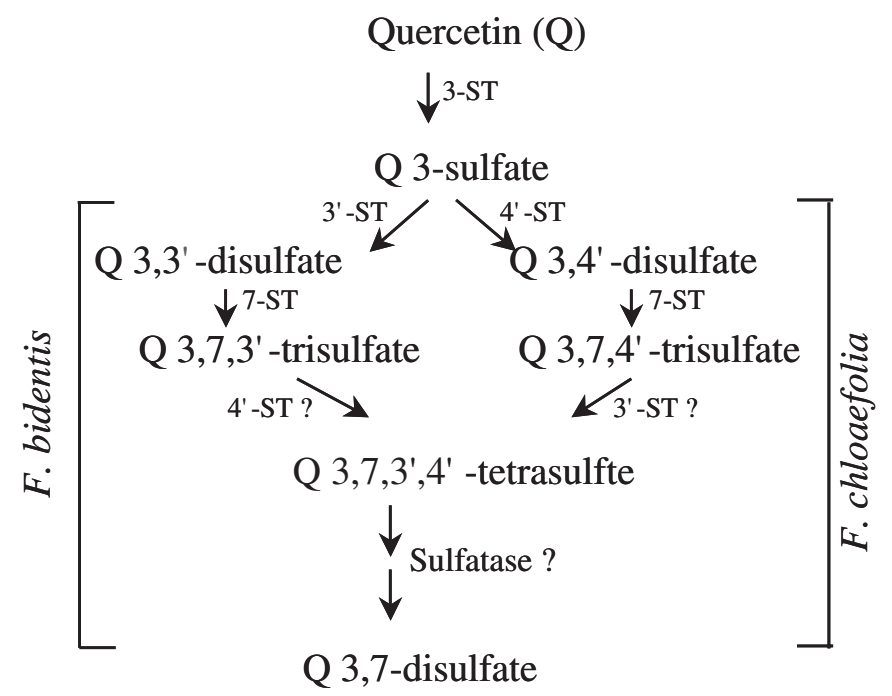

\section{Enzymatic prenylation of flavonoids and its biological significance}

Enzymatic prenylation of flavonoids is catalyzed by prenyltransferases (PTs) that utilize dimethylallyl pyrophosphate (DMAPP) or an appropriate alkyl analog as the prenyl donor. In contrast with the cytosolic (soluble) PTs involved in terpenoid biosynthesis (e.g., geranyl, farnesyl, and geranylgeranyl pyrophosphate synthases), aromatic PTs are membrane-associated and require a divalent cation, preferably $\mathrm{Mn}^{2+}$ or $\mathrm{Mg}^{2+}$, for catalytic activity.

The accumulation of (iso)prenylated flavonoids as natural plant constituents was only recently recognized. This form of conjugation was thought to be associated mostly with prenylated isoflavonoids and prenylated pterocarpans (ca. 300 compounds) of the Leguminosae (Tahara and Ibrahim 1995). However, a recent survey of the different classes of prenylated flavonoids, other than isoflavonoids and pterocarpans, indicated their common occurrence (ca. 700 compounds) as flavanones, flavones, and chalcones (Barron and Ibrahim 1996). They are of limited distribution in the plant kingdom and are restricted to a small number of genera belonging to a few unrelated plant families. Furthermore, the fact that flavanones represent branch-point intermediates in flavonoid biosynthesis may explain the relative abundance of prenylated flavanones in plants. In contrast to prenylated isoflavones and prenylated pterocarpans, which are inducible metabolites, isoprenylation of other flavonoid classes represents a constitutively expressed conjugation reaction. Gen- 
erally, most flavonoid compounds are $C$-prenylated, whereas $O$-prenylation is rare, and the former type occurs most frequently at positions 6 and (or) 8, as well as positions $3^{\prime}$ and (or) $5^{\prime}$ (Fig. 1B).

White lupin (Lupinus albus L.) roots accumulate a variety of mono- and di-prenylated isoflavones based on genistein and 2'-hydroxygenistein that are considered constitutive defense compounds, recently termed phytoanticipins (VanEtten et al. 1994). We demonstrated the enzymatic prenylation of these two isoflavones at positions 6, 8, and 3' (Fig. 1B) using solubilized microsomal pellets of white lupin roots and their cell suspension cultures (Laflamme et al. 1993). These PT activities were separated from a DOM [1- $O$ - $n$-dodecyl-( $\alpha$-Dglucopyranosyl)- $\beta$-D-pyranoside]-solubilized pellet by chromatography on a Fractogel (TMAE-EMD 650-S) ion exchange column. The prenylation reaction requires DMAPP and $12 \mathrm{mmol} / \mathrm{L} \mathrm{Mn}^{2+}$ for optimum activity in Tris- $\mathrm{HCl}$ buffer, $\mathrm{pH} 7.5$, and exhibits $K_{\mathrm{m}}$ values for both the prenyl donor and acceptor of 4-5 $\mu \mathrm{mol} / \mathrm{L}$. The differences observed in PT enzyme activity ratios, as to the source of enzyme (roots or cell cultures) and the type of detergent used (DOM, Nonidet, or Triton-X), suggest that prenylation at positions 6,8 , and $3^{\prime}$ is catalyzed by distinct enzymes (Laflamme et al. 1993). However, our efforts to purify any of the isoflavone PT activities of lupin and to clone of their respective genes were unsuccessful because the enzymes occur in very low abundance, are membrane-associated, and are difficult to solubilize while maintaining their catalytic activity.

Very recently, a PT derived from the microsomal fraction of Morus nigra L. cell cultures was shown to prenylate exclusively chalcones with a $2^{\prime}, 4^{\prime}$-dihydroxy substitution pattern and the isoflavone genistein (Vitali et al. 2003). The enzyme requires a divalent cation $\left(\mathrm{Mg}^{2+}\right.$ or $\left.\mathrm{Mn}^{2+}\right)$ for catalytic activity, with apparent $K_{\mathrm{m}}$ values of 63 and $142 \mu \mathrm{mol} / \mathrm{L}$ for DMAPP and the chlacone substrate, respectively.

However, Yazaki et al. (2002) reported the first isolation and characterization of a cDNA clone encoding geranyl diphosphate:4-hydroxybenzoate 3-geranyltransferase, an enzyme essential for the biosynthesis of the naphthoquinone shikonin, an antimicrobial metabolite of Lithospermum erythrorhizon roots. This gene was cloned using nested PCR techniques based on the conserved amino acid sequences among a number of polyprenyltransferases for ubiquinone biosynthesis. The availability of this cDNA clone may serve as a useful probe for future isolation of other plant-specific flavonoid PTs.

\section{Other isoflavone-related contributions}

We initiated a cell suspension culture of white lupin radicles, which served as a source of PT enzymes, and allowed the study of its potential application for the production of prenylated isoflavones (Hallard et al. 1992). We were able to effect their separation by HPLC (Gagnon et al. 1992a) and demonstrate their biosynthesis from labeled precursors (Gagnon et al. 1992b), as well as to investigate the effect of various abiotic and biotic elicitors on their accumulation and secretion (Gagnon and Ibrahim 1997). Interestingly, Rhizobium loti causes dramatic increases in the amounts of monoprenylated genistein and $2^{\prime}$ hydroxygenistein derivatives (Fig. 1B) in lupin, but not soybean or alfalfa symbiotic systems, suggesting that monoprenylated isoflavonoids may be involved in early Rhizobium infection of lupin roots.

The availability of several prenylated isoflavones (courtesy of Prof. Satoshi Tahara, Hokkaido University, Sapporo, Japan) prompted us to test their potential as molecular signals for nod gene induction in the Rhizobium lupini Lupinus albus symbiotic association (Gagnon and Ibrahim 1998). The screening method used was based on the measurement of $\beta$-galactosidase activity in $R$. lupini strains harboring nodC::lacZ fusions in the presence of authentic lupin isoflavones, carbohydrate-like inducers, or HPLCfractionated lupin seed effusates and root exudates. This work led to the discovery of two isomeric, hitherto unreported, 4-C sugar acids, erythronic and tetronic acids, which were also detected by HPLC in lupin seed effusates and root exudates. These two sugar acids result in low but significant increases in $\beta$-galactosidase activity. However, compared with other prenylated isoflavones, lupiwighteone (Fig. 1B) exerts its inducing effect in synergy with either of the sugar acids. Labeling studies with $\left[{ }^{14} \mathrm{C}\right]$ lipochitin oligosaccharide (LCO) precursors confirmed the inductive role of both sugar acids in promoting LCO biosynthesis in $R$. lupini cultures. As a control, when tested with nodC::lacZ fusions, tetronic acid resulted in nod gene induction in Sinorhizobium meliloti, and both luteolin (Fig. 1A) and tetronic acid led to further increases in $S$. meliloti nod gene expression, thus confirming the results obtained with $R$. lupini (Gagnon and Ibrahim 1998).

We also demonstrated that root nodules from mature lupin plants accumulate prenylated derivatives of both genistein and 2'-hydroxygenistein, with the predominance of $2^{\prime}$ hydroxylupalbigenin. Immunogold localization using monospecific polyclonal IgGs (Ibrahim 1990), revealed an association of 2'-hydroxylupalbigenin with the establishment of early symbiotic structures, as well as with the bacteroids themselves. The discrete location of the diprenylisoflavone label in specialized cytoplasmic organelles suggests that its compartmentalization within the wall is mediated by membrane vesicles (Grandmaison and Ibrahim 1995). These results, together with the fact that prenylated isoflavonoids reduce the in vitro growth rate of a number of Rhizobium species, suggest that these metabolites may modulate these symbiotic associations (Gagnon et al. 1995).

We isolated and characterized an abundant $17-\mathrm{kDa}$ protein from healthy root tissues of white lupin. The corresponding cDNA clone, which exhibits a high amino acid sequence similarity to the pathogenesis-related (PR-10) proteins found in other leguminous species (Bantignies et al. 2000), contains an open reading frame encoding a polypeptide of 158 amino acids, with a predicted molecular mass of $16905 \mathrm{Da}$ and a pI of 4.7. The recombinant protein, purified to near homogeneity, is immunorecognized by an anti-pea PR-10 antibody, and exhibits ribonucleolytic activity against several RNA preparations including that from lupin root; it is therefore considered a member of class II ribonucleases. Strong expression of the LaPR-10 protein at all stages of root development, as well as in other organs of lupin, suggests that it is a component of the constitutive, pre-infectional repertoire of the plant's defense mechanism (Bantignies et al. 2000). 


\section{Molecular cloning of flavonoid enzymes}

\section{Flavonol $\boldsymbol{O}$-methyltransferases}

OMT cDNAs encoding the methylation of a variety of flavonoids have been isolated and chacterized from several plants (reviewed by Ibrahim and Muzac 2000), including Catharanthus roseus (Cacace et al. 2003; Schröder et al. 2004) and Mentha xpiperata (Willits et al. 2004). We used degenerate nucleotides designed from conserved regions of several known OMTs, and PCR to isolate several flavonol OMT cDNA clones from a $C$. americanum library. One of these clones FOMT $3^{\prime} / 5^{\prime}$ (345 amino acids, $37.6 \mathrm{kDa}$ ) encodes the specific $3^{\prime}-/ 5^{\prime}$-methylation of the flavonoid inter-

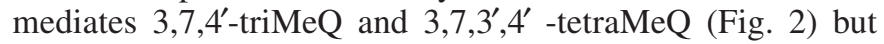
does not accept the di- or tri-methylated derivatives or the parent aglycone as substrates (Gauthier et al. 1996; Séguin et al. 1998), indicating that this cDNA clone is involved in the biosynthesis of polymethylated flavonols in this tissue. Since this methylation step occurs at the aglycone and not the 2'-glucoside level, it may be considered a permissive characteristic of the recombinant protein, whereas $5^{\prime}$ methylation takes place after 2'-glucosylation of the trimethylated intermediate (Fig. 2).

Another clone, FOMTx, which differs from FOMT3'/5' by a single amino acid residue (Ser286Arg), exhibits no enzymatic activity towards any of the flavonoid substrates tested. Replacement of Ser286 in FOMT3'/5' with either Ala, Leu, Lys, or Thr almost abolishes OMT enzyme activity. In contrast with FOMT3' $/ 5^{\prime}$, no affinity labeling is possible using $\left[{ }^{14} \mathrm{C}\right]$ AdoMet with any of the mutant recombinant proteins, indicating that Ser286 is required for cosubstrate binding and catalysis (Kornblatt et al. 2004). These results are corroborated by the isothermal titration microcalorimetry measurements. Moreover, circular dichroism spectra rule out any significant conformational differences in the secondary structures of both FOMT3 $/ 5^{\prime}$ and FOMTx. Modeling FOMT3 $1 / 5^{\prime}$ on the structure of chalcone OMT (Zubieta et al. 2001) indicates that Ser286 is greater than $10 \AA$ ( $1 \AA=$ $0.1 \mathrm{~nm})$ from any of the residues of the active site or the AdoMet binding site of FOMT3'/5'. In addition, residues 282-290 are conserved in most Chrysosplenium OMTs. These residues form a large part of the subunit interface, and at least five of these residues are within $4 \AA$ of the opposite subunit. It seems, therefore, that mutations in Ser286 exert their effect by altering the contacts between the subunits, and that these contacts are necessary for maintaining the integrity of the AdoMet binding site and active site of this group of enzymes (Kornblatt et al. 2004).

Two other cDNA clones, OMT1 and OMT2, which translate into 343 amino acids with a calculated $M_{\mathrm{r}}$ of $37.9 \mathrm{kDa}$, differ from each other in three amino acid residues (Ser27Cys, Ala198Thr, Gln368Lys). Both clones encode the 3 -methylation of both quercetin (a flavonol) and luteolin (a flavone), as well as the respective $3 / 5$ methylation of the hydroxycinnamic acids, caffeic and 5-OH-ferulic acids, although to a different extent (Gauthier et al. 1998). However, the dual substrate specificity of both OMTs is not unexpected, since their sequences differ from that of the HCA OMT by only 32 conserved amino acids, which are located in the regions proposed for substrate specificity. The variations in amino acid substitutions may be responsible for the dual specificity of both OMTs. The high sequence similarity between the phenylpropanoid and flavonoid OMTs (Ibrahim et al. 1998) indicates that the genes encoding these two classes of enzymes share a close evolutionary relationship. Less than $1 \%$ change in the amino acid sequences of OMT1 and OMT2 results in a modified substrate preference between these two gene products. This illustrates a plausible scenario for incremental change in protein structure by which organisms develop new metabolic capabilities.

A cDNA clone (363 amino acids, $40.5 \mathrm{kDa}$ ), was recently isolated from Arabidopsis thaliana by the yeast two-hybrid system, and initially considered as a HCA OMT, based on high amino acid sequence similarity (Zhang et al.1997). When it was functionally expressed in E. coli, the recombinant protein was identified as a flavonol 3'-OMT that does not accept HCAs as substrates (Muzac et al. 2000), indicating that sequence homology-based comparison is not sufficient for the proper characterization of gene function.

\section{Partially methylated flavonol 6-hydroxylase}

Tryptic digestion and microsequencing of the native flavonol 6-hydroxylase (F6H) (Anzellotti and Ibrahim 2000) provided several peptides with significant amino acid sequence similarity to other known flavonoid oxoglutaratedependent dioxygenases (ODDs). PCR with different degenerate primer combinations, based on these internal peptide sequences, enabled the isolation of a 1245-bp cDNA fragment, termed $c F 6 H$ that contains the $3^{\prime}$-end of the putative cDNA clone but lacks the translation start site. The truncated clone translates into a 376 amino acid polypeptide with a predicted $M_{\mathrm{r}}$ of 43-45 $\mathrm{kDa}$, suggesting that the fragment lacks 10-15 N-terminal amino acid residues. In addition, internal peptide sequences that were obtained from mass spectral analysis are consistent with the predicted protein sequence, confirming its authenticity as a fragment of the gene encoding F6H (Anzellotti and Ibrahim 2004). Recombinant proteins, obtained from expression of the gene in both prokaryotic and eukaryotic systems, exhibit the same substrate specificity, as well as the cosubstrate and cofactor requirements as those of the native plant $\mathrm{F} 6 \mathrm{H}$. The genomic region encoding this enzyme possesses two introns at conserved locations for this class of enzymes, suggesting that ODD sequences arose through divergence from a common ancestor. In addition, the genomic region of $\mathrm{F} 6 \mathrm{H}$ is present as a single copy in the $C$. americanum genome, suggesting a regulatory role of this gene in the 6-hydroxylation of partially methylated flavonols compared with that at the 2 position (Fig. 2). In view of the wide range of functions that ODDs catalyze, the molecular characterization of $F 6 H$ and related genes is significant because it may enable identification of common structure or reaction mechanisms, as well as reveal motifs or residues that determine reaction type and (or) substrate preference (Anzellotti and Ibrahim 2004).

\section{Flavonol sulfotransferases}

The availability of a partial peptide sequence of the purified flavonol 3-ST (Fig. 3) and a monospecific polyclonal antibody raised against it (Varin and Ibrahim 1992), allowed the isolation of cDNA clones for flavonol 3- and 4'-STs from an expression library prepared from the terminal buds of F. chloraefolia. The full-length clones, with open reading 
frames of 933 and $960 \mathrm{bp}$, encode polypeptides containing 311 and 320 amino acids, corresponding to a $M_{\mathrm{r}}$ of 36442 and 37212 Da for the 3-ST and 4'-ST, respectively, (Varin et al. 1992). The recombinant proteins expressed in E. coli exhibit the same substrate specificities as those of the 3- and $4^{\prime}$-ST enzymes isolated from the intact plant. Comparison of the deduced amino sequence of the two clones reveals an overall identity of $69 \%$ between the two proteins, and both share significant sequence similarities with rat liver hydroxysteroid ST, bovine placenta estrogen ST, and aryl STs found in animal tissues, suggesting an evolutionary relationship between plant and animal STs.

Another flavonol 3-ST cDNA clone was isolated and characterized from $F$. bidentis cell suspension cultures (Ananvoranich et al. 1994). Its nucleotide and deduced amino acid sequences exhibit $92.5 \%$ and $95.5 \%$ identities, respectively, with those of the $F$. chloraefolia flavonol 3-ST. The recombinant protein exhibits highest relative enzyme activity $(100 \%)$ with quercetin and rhamnetin $(75 \%)$ and lowest (10\%) with isorhamnetin. It does not accept kaempferol or any of the flavanones or flavones tested as substrates. The low 3-ST activity obtained with isorhamnetin is possibly due to steric hindrance of the bulky methyl group at position $3^{\prime}$. In addition, treatment of the cell cultures with $25 \mu \mathrm{mol} / \mathrm{L} 2,4-\mathrm{D}$ induces both flavonol 3-ST enzyme activity and ST-mRNA transcript levels within $3 \mathrm{~h}$ of treatment, reaches its maximum after $24 \mathrm{~h}$, and remains elevated for up to $48 \mathrm{~h}$. Induction of the 3-ST enzyme is inhibited by actinomycin-D, suggesting that the hormonal influence is at the level of gene expression. On the other hand, inhibition of 3-ST activity by the sulfated product is not at the transcriptional level and more likely occurs at the enzyme level through feedback regulation.

An attempt was made to utilize the flavonol 3-ST (F3ST) cDNA clone to reduce the glucosinolate ( $S$-containing glucosides) content of Brassica napus (Ibrahim et al. 1994). Rather than using antisense RNA technology to block their biosynthesis, we designed a strategy that involves the introduction of the Flaveria F3ST gene into Brassica with the aim of creating novel, innocuous metabolites, especially flavonol 3-sulfates. This strategy is based on the assumption that the foreign F3ST enzyme competes with the native desulfoglucosinolate sulfotransferase (DGST), the last step in glucosinolate biosynthesis, for the limited endogenous pool of the sulfate donor PAPS. Since the affinities of the former enzyme for its substrate and cosubstrate is 1 to 2 orders of magnitude higher than those of the DGST, it is expected that sulfonation of the endogenous flavonols in canola (kaempferol and isorhamnetin) should predominate over that of the DGs. Expression of the recombinant F3ST could not be achieved in the target plant, in spite of the accumulation of small amounts of Q 3-S. Furthermore, northern and western blot analyses indicated that even transgenic plants exhibiting highest F3ST activity do not hybridized with the F3ST mRNA or accumulate enough enzyme protein for immunological detection. This may be due to high instability of the F3ST mRNA, in addition to the low efficiency of transformation and regeneration of the transgenic plants. Cloning of the gene encoding DGST has recently been reported from Arabidopsis thaliana, and is presumed to occur also in Brassica spp. (Piotrowski et al. 2004). However, the lack of expression of F3ST gene in canola may be due to cosuppression by the endogenous DGST gene.

An alternative strategy utilized the tryptophan decarboxylase (TDC) gene to create a new metabolite, tryptamine, that reduces the indolylglucosinolate levels in canola by up to $80 \%$ of the controls (Ibrahim et al. 1994). In addition, mature seeds produced from transgenic canola lines accumulate $3 \%$ and $50 \%$ of the indolylglucosionlates present in the controls by transformed lines exhibiting highest and lowest TDC enzyme activities, respectively, while the levels of the allylglucosinolates remain constant. These results clearly indicate the feasibility of redirecting tryptophan away from indolylglucosinolate biosynthesis by the heterologous expression of TDC activity in canola without affecting the overall levels of allylglucosinolates (Chavadej et al. 1994).

\section{Phylogenetic relationships of flavonoid enzymes}

Molecular phylogeny has become a powerful new tool in protein function prediction. This approach is based on evolutionary principles and is a more reliable predictor of protein function than the traditional sequence similarity searches (Eisen and Wu 2002). The phylogenetic trees based on DNA or protein sequence data of biochemically characterized genes of interest are reconstructed and used as a framework to predict the substrate specificity of novel, putative gene sequences with respect to their function. We have used this approach to reconstruct the phylogeny of the biochemically characterized OMTs and ODDs.

\section{$O$-Methyltransferases}

We proposed the five consensus sequence motifs (regions I-V) as a signature for most, if not all, plant OMTs (Ibrahim 1997; Ibrahim et al. 1998). These motifs are rich in glycine (ca. 28\%) and contain several hydrophobic residues. Motifs I and IV have been proposed as the binding sites for AdoMet and metal ion, respectively. This indicates that AdoMetdependent plant OMTs constitute a distinct superfamily with characteristic motifs (Ibrahim and Muzac 2000), which will undoubtedly facilitate the identification of other yet undiscovered OMT sequences.

The recent elucidation of the crystal structure of several OMT proteins (Zubieta et al. 2001, 2002; Yang et al. 2004) revealed the nature of the amino acids involved in the binding of AdoMet and $\mathrm{Mg}^{2+}$, as well as those involved in substrate binding and catalysis. These domains are similar to the DNA methyltransferase subfamily, suggesting that all AdoMet-dependent, functionally analogous enzymes have a common structure, and probably evolved from a common ancestor in spite of their different substrate specificities.

The essential roles that OMTs play in secondary metabolite synthesis and the availability of $>16$ biochemically characterized flavonoid OMTs, as compared with half that number four years ago (Ibrahim and Muzac 2000), prompted us to reconstruct a framework phylogenetic tree (Fig. 4) for evolutionary studies (Lam et al. 2004). This unrooted tree has three distinct clusters of OMTs. One cluster incorporates the stress-induced isoflavonoid OMTs that utilize the structurally related isoflavanones, isoflavones, and pterocarpans as substrates, with the isoflavanone and isoflavone pairs oc- 
Fig. 4. Phylogenetic analysis of flavonoid $O$-methyltransferases (OMTs). Sequences retrieved from the databases (accession numbers in italics) were aligned using CLUSTAL-W and PHYLIP output formats, and then transferred into McClade 4.0 and PAUP 4.0 for tree building and analysis, as described by Lam et al. (2004). Mentha flavonol 8-OMT (AY337459), Catharanthus flavonol 3'- and 5'-OMT (AY127568), Pisum pterocarpan 3-OMT (U69553), Glycyrrhiza isflavanone 4'-OMT (AB091684), Lotus isoflavanone 4'-OMT (AB091686), Medicago isoflavone 7-OMT (U97125), Glycyrrhiza isoflavone 7-OMT (AB091685), Hordeum flavone 7-OMT (X77467), Mentha flavonoid 7-OMT (AY337457), Mentha flavonoid 7-OMT (AY337458), Mentha flavonoid 4'-OMT (AY337461), Chrysosplenium flavonoid 3'/5'-OMT (U16794), Chrysosplenium flavonol 3'-OMT (U16793), Arabidopsis flavonol 3'-OMT (U70424), Mentha flavonoid 3'-OMT (AY337460), Medicago chalcone 2'-OMT (L10211). Numbers represent bootstrap percent values.

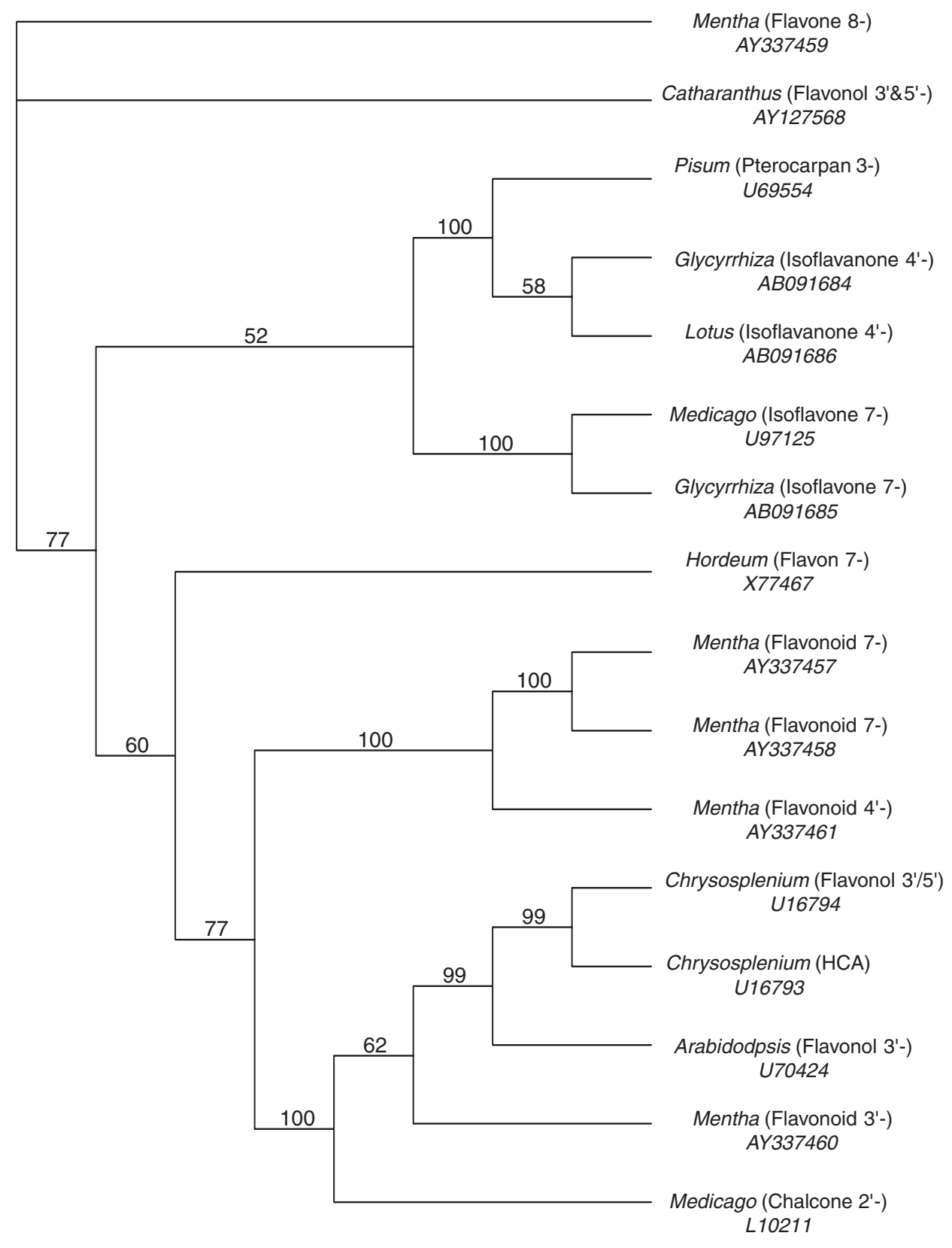

cupying sister clades. A second cluster combines the peppermint and barley flavonoid 7- and 4'-OMTs. It is interesting to note that both positions of methylation are equivalent, being para to the flavonoid A-ring and B-ring side chains, respectively, and that position 3 of pterocarpans is equivalent to position 7 of isoflavones. The third cluster unites the flavonol 3'- and 3'/5'-OMTs of Arabidopsis, Chrysosplenium, and Mentha; these methylated positions are meta to the Bring side chain. The three remaining sequences, the alfalfa- chalcone 2'-OMT, peppermint-flavonol 8-OMT, and the Catharanthus-flavonol $3^{\prime}$ - and 5'-OMT (the latter catalyzes two sequential methylations), are located as monophyletic clades at both ends of the tree (Fig. 4), mainly because of their low sequence homologies to the other OMTs and some structural peculiarities of their methyl acceptor molecules. These results demonstrate that such phylogenetic analysis can allow function prediction of putative OMT genes, based not only on protein sequence homology but, more so, on 
stereochemical considerations of the methyl acceptor molecules. Although OMTs have a common 3-D structure (protein fold), they may have peripheral elements of secondary structure and turn regions that differ in size and conformation depending on their evolutionary origin. Therefore, a 3-D structure-based phylogenetic tree, if generated, may help explain some of the ambiguities often observed with the analyses based only on primary sequence structure.

\section{Flavonol 6-hydroxylase}

$c F 6 H$ exhibits highest amino acid sequence similarity to flavanone 3-hydroxylase $(\mathrm{F} 3 \mathrm{H})$ homologs, thus prompted us to investigate its relationship to other oxoglutaratedependent dioxygenases (ODDs). Since homologous genes encoding biochemically related proteins are usually clustered in related subgroups, it is not unexpected, therefore, that $c F 6 H$ clusters with the $F 3 H$ group of genes (Fig. 5), albeit at a position distal to those homologs from other species. $\mathrm{F} 6 \mathrm{H}$ exhibits a high degree of conservation of the motifs required for iron and cosubstrate binding, common to the ODD group of enzymes, suggesting an evolutionary relationship with these biosynthetically related proteins (Anzellotti and Ibrahim 2004).

At the phylogenetic level, ODDs comprise a superfamily with numerous subgroups, whose subsets are defined by shared motifs in encoded proteins such as those involved in flavonoid biosynthesis. These motifs often comprise the active site of the enzyme and (or) the binding domains for substrates and cofactors. In addition, the degree of similarity between genes encoding dioxygenases with different substrate preferences suggests a common reaction mechanism. The molecular characterization of $\mathrm{F} 6 \mathrm{H}$ and related ODDs could identify potential similarities in structure or reaction mechanisms, as well as reveal motifs or residues that may determine reaction type and (or) substrate preference (Anzellotti and Ibrahim 2004).

\section{3-D structural aspects of Arabidopsis flavonol 3'-O-methyltransferase}

Most plant OMTs share similar structural and catalytic characteristics (Schubert et al. 2003), prompting us to investigate the predicted three-dimensional (3-D) structure of Arabidopsis flavonol 3'-OMT (AtOMT1), with the aim of explaining its substrate specificity. This was carried out by homology-based modeling using the 3-D structure of caffeic acid OMT (COMT) (Zubieta et al. 2002) as a template (Yang et al. 2004), since both proteins share a high amino acid sequence similarity and identity $(88.5 \%$ and $80 \%$, respectively) (Muzac et al. 2000). COMT consists of $20 \alpha-$ helices and nine $\beta$-sheets, whereas AtOMT1 has 16 and 9, respectively. Nevertheless, both proteins exhibit a similar structure (Figs. 6A-6C), and all but one of the amino acid residues surrounding the active sites are similar in their primary sequences (Figs. 6D, 6E). That amino acid difference in the binding sites of both proteins, Ile 316 in COMT has one more methylene group than the corresponding Val314 of AtOMT1, which accounts for a molar volume of $17.6 \mathrm{~cm}^{3}$ and may be responsible for the substrate preference of both proteins. This is supported by the fact that the phenylpropenoid, eugenol, and chavicol OMTs, which differ in
Fig. 5. Phylogenetic analysis of some representative 2oxoglutarate-dependent dioxygenases involved in the biosynthesis of flavonoid compounds, including the Chrysosplenium partially methylated flavonol 6-hydroxylase (F6H Chryso, shown in bold). Sequences retrieved from the databases (accession numbers in italics) were aligned using CLUSTAL-W and PHYLIP output formats, and then transferred into McClade 4.0 and PAUP 4.0 for tree building and analysis as described by Anzellotti and Ibrahim (2004). Potato FLS (X92178); petunia FLS (Z22543); parsley FLS (AY230249); Arabidopsis FLS (U84259); Arabidopsis ANS (U70478); apple ANS (X71360); carrot ANS (AF184273); potato F3H (AY102035); petunia F3H (X60512); apple F3H (X69664); parsley FSI (AY230247); parsley F3H (AY230248); Hyoscyamus hyoscyamine 6b-hydroxylase (M62719); Catharanthus desacteoxyvindoline 4-hydroxylase (U71604). ANS, anthocyanidin synthase; F3H, flavanone 3-hydroxylase, FSI, flavone synthase I; FLS, flavonol synthase. Numbers represent bootstrap percent values.

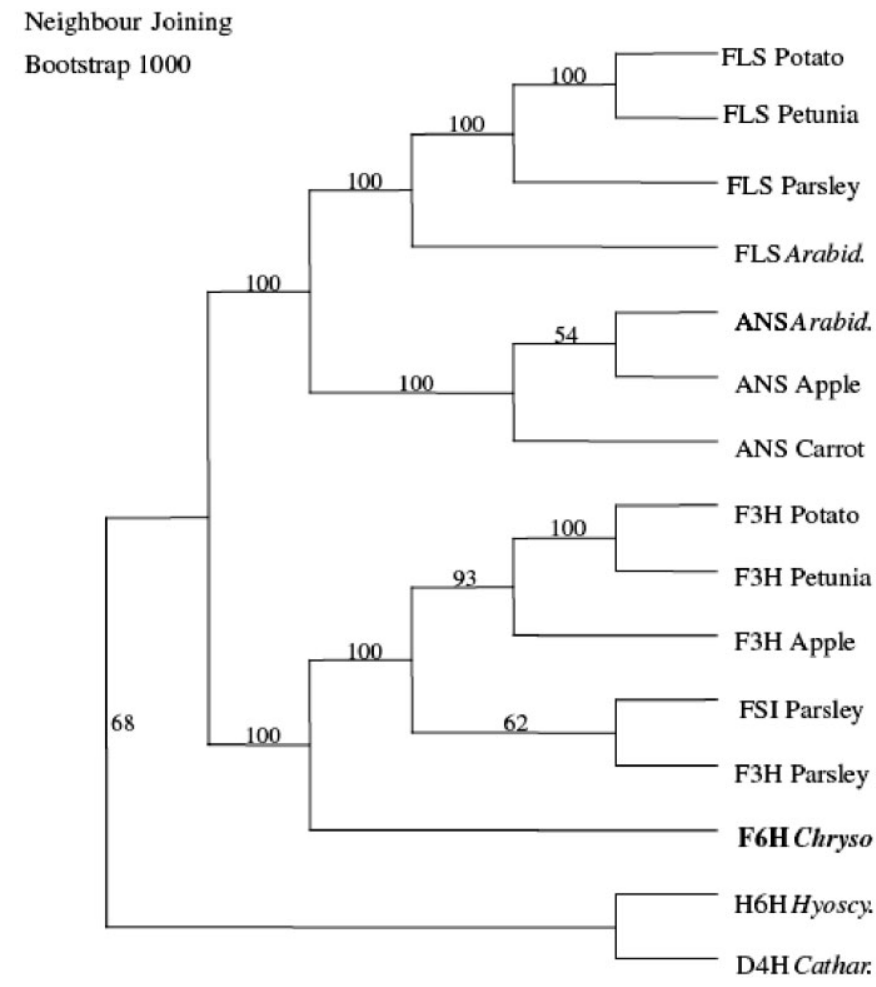

their substrate binding sites by one amino acid, exhibit opposite substrate preferences by switching that residue in both proteins (Gang et al. 2002). In addition, the fact that the substrate binding site in both COMT and AtOMT1 is situated within a cleft that a substrate molecule must pass through to dock with the enzyme, indicates that the residues positioned inside the cleft will affect the substrate by limiting the entrance size. In fact, Gly326 and Asp270, which form the gate of the cleft, are separated by a distance of $5 \AA$ in COMT and $7.5 \AA$ in AtOMT1, distances that compare well with the relative sizes of both substrates, caffeic acid and quercetin, respectively. Therefore, in spite of the high sequence homology of both proteins, their distinct substrate specificity seems to be due to the substrate binding site difference and paricularly, the size of the cleft gate surrounding the binding site (Yang et al. 2004). 
Fig. 6. (A) Three-dimensional structures of alfalfa caffeic acid $O$-methyltransferase (COMT). (B) The predicted structure of Arabidopsis flavonol 3'-O-methyltransferase (AtOMT1) based on homology modeling with COMT as a template. (C) Superimposition of both COMT (green) and AtOMT1 (purple). (D) The binding site of COMT products, ferulic acid, and AdoHcy. (E) The binding site of AtOMT1 products, isorhamnetin, and AdoHcy. The amino acid residue difference in both COMT (D) and AtOMT1 (E) is circled. (From Yang et al. 2004, reproduced with permission of J. Mol. Graphics Modell., Vol. 23, pp. 80 and 82, (C) 2004 Elsevier.)
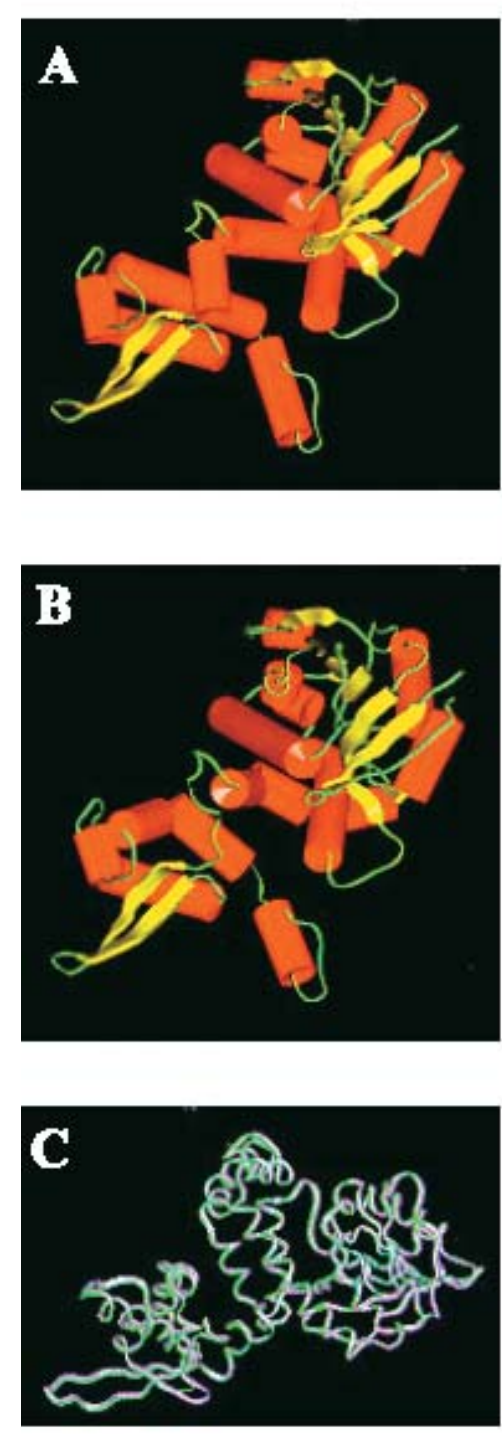
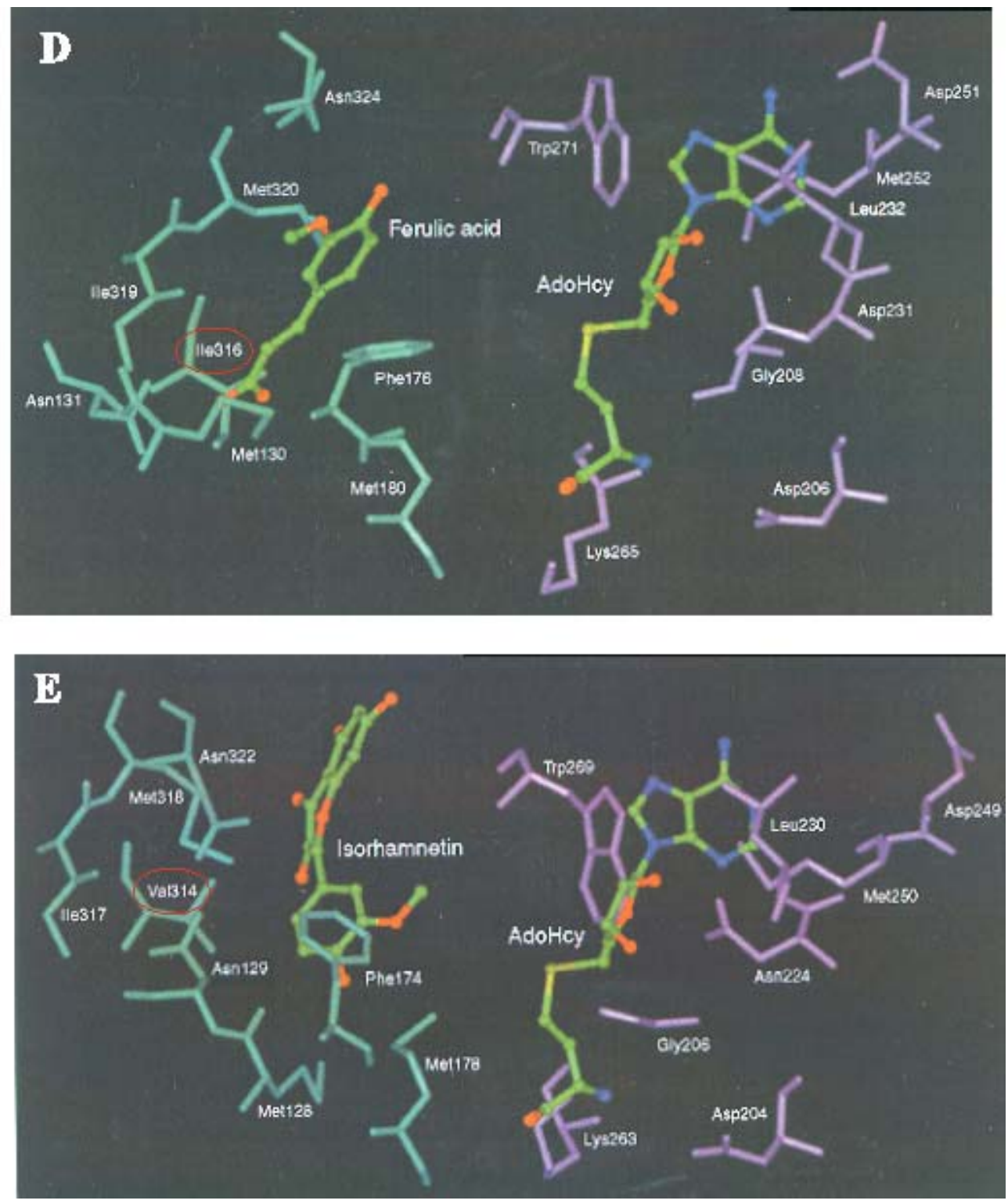

\section{Perspectives}

Plants represent an important renewable source of food, feed, and fiber, as well as the production of a rich variety and an enormous diversity of flavonoid compounds, which are known for their essential roles in several developmental and physiological processes and for their potential health benefits. It is no wonder that they became an attractive subject of research that started with traditional plant breeding and continues through the use of genetic engineering. Through cloning and characterization of the structural flavonoid genes and the use of diverse approaches, including over-expression, down-regulation, antisense suppression, and co-suppression of target genes (Winkel-Shirley 2001), the potential of developing plant species with optimized, tailormade flavonoid levels and compositions is becoming a reality. The recent discovery that the maize transcription factors/regulatory genes, $R$ (proto-oncogene MYC-like) and $C 1$ (proto-oncogene MYB-like), exert a coordinate control of the biosynthetic genes (Holton and Cornish 1995) has presented a new opportunity for increasing the levels and diversity of flavonoids in plants (Schijlen et al. 2004). These transcriptional factors appear to be functionally conserved among plant species during evolution, enabling their introduction into a variety of species with the aim of altering their flavonoid composition.

However, there remain a number of serious challenges that require further investigation, especially with regards to 
the modifying enzymes and their corresponding genes that are responsible for the glycosylation, methylation, and prenylation reactions. These reactions are important for flavonoid stability, cellular distribution, and bioactivity (Schijlen et al. 2004). Another important point concerns the potential negative impact of introducing a new branch-point enzyme on the endogenous flavonoid pathway with the aim of down-regulating a particular metabolite or creating another, as well as controlling the metabolic flux within the targeted pathway (Ibrahim et al. 1994). Since flavonoids play important roles in the physiology and development of plants, disruption or modification of existing pathways may result in pleiotropic effects, such as altered growth patterns, enhanced susceptibility to stress, and (or) decreased fertility. Finally, there is increasing evidence for the association of phenylpropanoid and flavonoid enzymes into discrete metabolons (Stafford 1990), which may complicate metabolic engineering strategies by limiting the access of endogenous substrates to the introduced target enzymes, interfering with the metabolic channeling and (or) catalytic efficiency, or affecting the end-product flux. On the other hand, the results of recent attempts to modify flavonoid profiles of plants (Forkmann and Martens 2001; Schijlen et al. 2004) provide a great incentive to continue efforts aimed at developing plants with more desirable characteristics.

\section{Acknowledgements}

I wish to sincerely thank all the men and women - graduate students, research associates, and guest researchers who collaborated with me over several years to bring about the contributions reported in this review. This would not have been possible without the generous, uninterrupted financial support of the Natural Sciences and Engineering Research Council of Canada since 1968 and the Department of Higher Education, Government of Québec since 1972, to which I am very grateful. I wish also to thank Drs. S. Dayanandan and D. Anzellotti for careful reading of the manuscript, the reviewers for their precision and constructive comments, and Elsevier Publishers for permission to reproduce Fig. 6.

\section{References}

Ananvoranich, S., Varin, L., Gulick, P., and Ibrahim, R.K. 1994. Cloning and regulation of flavonol 3-sulfotransferase in cell suspension cultures of Flaveria bidentis. Plant Physiol. 106: 485491.

Anzellotti, D., and Ibrahim, R.K. 2000. A novel flavonol 2oxoglutarate-dependent dioxygenase: affinity purification, characterization and kinetin properties. Arch. Biochem. Biophys. 382: $161-172$.

Anzellotti, D., and Ibrahim, R.K. 2004. Molecular characterization and functional expression of flavonol 6-hydroxylase. BMC Plant Biol. [online] 4: 20. doi: 10.1186/1471-2229-4-20

Bajaj, K.L., De Luca, V., Khouri, H.E., and Ibrahim, R.K. 1983. Partial purification and properties of flavonol ring-B $O$ glucosyltransferases from Chrysosplenium americanum. Plant Physiol. 72: 891-896.

Bantignies, B., Séguin, J., Muzac, I., Dédaldéchamp, F., Gulick, P.J., and Ibrahim, R.K. 2000. Direct evidence for ribonucleolytic activity of a PR-10-like protein from white lupin roots. Plant Mol. Biol. 42: 871-881.
Barron, D., and Ibrahim 1986. Novel flavonol sulfates from Flaveria chloraefolia. Bull. Liaison Groupe Polyphenols, 13: 540-545.

Barron, D., and Ibrahim, R.K. 1987a. Quercetin- and patuletin 3,3'disulfates from Flaveria chloraefolia. Phytochemistry, 26: 1181-1184.

Barron, D., and Ibrahim, R.K. 1987b. 6-Methoxyflavonol 3monosulfates from Flaveria chloraefolia. Phytochemistry, 26: 2085-2088.

Barron, D., and Ibrahim, R.K. 1987c. Synthesis of flavonoid sulfates. I. Stepwise sulfation of positions 3, 7 and $4^{\prime}$ using $\mathrm{N}, \mathrm{N}^{\prime}$ dicyclohexylcarbodiimide and tetrabutylammonium hydrogen sulfate. Tetrahedron, 43: 5197-5202.

Barron, D., and Ibrahim, R.K. 1988a. Synthesis of flavonoid sulfates. II. The use of aryl sulfatase in the synthesis of flavonol 3sulfates. Z. Naturforsch. 43c: 625-630.

Barron, D., and Ibrahim, R.K. 1988b. Synthesis of flavonoid sulfates. III. Synthesis of $3^{\prime}, 4^{\prime}-o$-disulfates using sulfur trioxidetrimethylamine complex and of 3 '-sulfates using aryl sulfatase. Z. Naturforsch. 43c: 631-635.

Barron, D., and Ibrahim, R.K. 1988c. Hydrochloric acid and aryl sulfatase as reagents for uv spectral detection of 3- and 4'-sulfated flavonoids. Phytochemistry, 27: 2335-2338.

Barron, D., and Ibrahim, R.K. 1988d. Ombuin 3-sulfate from Flaveria chloraefolia. Phytochemistry, 27: 2362-2363.

Barron, D., and Ibrahim, R.K. 1996. Isoprenylated flavonoids: a survey. Phytochemistry, 43: 921-982.

Barron, D., Colebrook, L., and Ibrahim, R.K. 1986. An equimolar mixture of quercetin 3-sulfate and patuletin 3-sulfate from Flaveria chloraefolia. Phytochemistry, 25: 1719-1721.

Barron, D., Varin, L., Ibrahim, R.K., Harborne, J.B., and Williams, A.C. 1988. Sulfated flavonoids: an update. Phytochemistry, 27: 2375-2395.

Bohm, B.A. 1998a. Flavonoid functions in nature. In Introduction to flavonoids. Chemistry and biochemistry of organic natural products. Vol. 2. Edited by B.A. Bohm. Harwood Academic Publishers, Amsterdam. pp. 339-364.

Bohm, B.A. 1988b. Human uses of flavonoids. In Introduction to flavonoids. Chemistry and biochemistry of organic natural products. Vol. 2. Edited by B.A. Bohm. Harwood Academic Publishers, Amsterdam. pp. 365-393.

Brisson, L., Vacha, W., and Ibrahim, R.K. 1986. Localization of partially methylated flavonol glucosides in Chrysosplenium americanum. II. Immunofluorescense. Plant Sci. 44: 559-605.

Brisson, L., Rideau, M., and Ibrahim, R.K. 1988. Tissue culture of Chrysosplenium americanum and its potential for flavonoid production. Plant Cell Rep. 7: 130-133.

Brunet, G., and Ibrahim, R.K. 1980. O-Methylation of flavonoids by cell-free extracts of calamondin orange. Phytochemistry, 19: 741-746.

Cacace, S., Schröder, G., Wehinger, E., Strack, D., and Schmidt, J., and Schröder, J. 2003. A flavonol $O$-methyltransferase from Catharanthus roseus performing two sequential methylations. Phytochemistry, 62: 127-137.

Charest, P.-M., Brisson, L., and Ibrahim, R.K. 1986. Ultrastructural features of flavonoid accumulation in leaf cells of Chrysosplenium americanum. Protoplasma, 134: 95-101.

Chavadej, S., Brisson, N., McNeil, J.N., and De Luca, V. 1994. Redirection of tryptophan leads to production of low indole glucosinolate canola. Proc. Natl. Acad. Sci. U.S.A. 91: 21662170 .

Chrispeels, M.J. 1980. The endoplasmic reticulum. In The biochemistry of plants. Vol. 1. Edited by N.E. Tolbert. Academic Press, New York. pp. 389-412. 
Collins, F.W., De Luca, V., Ibrahim, R.K.,Voirin, B., and Jay, M. 1981. Polymethylated flavonol synthesis in Chrysosplenium americanum: identification and enzymatic synthesis. Z. Naturforsch. 36c: 730-736.

De Carolis, E., and Ibrahim, R.K. 1989. Purfication and kinetics of two phenylpropanoid $O$-methyltransferase activities from Brassica oleracea. Biochem. Cell Biol. 67: 763-769.

De Luca, V., and Ibrahim, R.K. 1982. Characterization of three distinct $O$-methyltransferases from Chrysosplenium americanum. Phytochemistry, 21: 1537-1540.

De Luca, V., and Ibahim, R.K. 1985a. Enzymatic synthesis of polymethylated flavonols in Chrysosplenium americanum. I. Partial purification and some properties of $S$-adenosyl-Lmethionine:flavonol 3-, 6-, 7-, and 4'-O-methyltransferases. Arch. Biochem. Biophys. 238: 595-605.

De Luca, V., and Ibrahim, R.K. 1985b. Enzymatic synthesis of polymethylated flavonols in Chrysosplenium americanum. II. Substrate interaction and product inhibition studies of flavonol 3-, 6- and 4'-O-methyltransferases. Arch. Biochem. Biophys. 238: $606-618$.

Dixon, R.A. 1999. Isoflavonoids. In Comprehensive natural products chemistry. Vol. 1. Edited by U. Sankawa. Elsevier, Amsterdam. pp. 773-823.

Eisen, J.A., and Wu, M. 2002. Phylogenetic analysis and gene functional prediction: phylogenomics in action. Theor. Popul. Biol. 61: 481-487.

Forkmann, G., and Heller, W. 1999. Biosynthesis of flavonoids. In Comprehensive natural products chemistry. Vol. 1. Edited by U. Sankawa. Elsevier, Amsterdam. pp. 713-748.

Forkmann, G., and Martens, S. 2001. Metabolic engineering and applications of flavonoids. Curr. Opin. Biotechnol. 12: 155-160.

Gagnon, H., and Ibrahim, R.K. 1997. Effects of various elicitors on the accumulation and secretion of isoflavonoids in white lupin. Phytochemistry, 44: 1463-1467.

Gagnon, H., and Ibrahim, R.K. 1998. Aldonic acids: a novel family of nod gene inducers of Mesorhizobium loti, Rhizobium lupini and Sinorhizobium meliloti. Mol. Plant-Microbe Interact. 11: 988-998.

Gagnon, H., Séguin, J., Bleichert, E., Tahara, S., and Ibrahim, R.K. $1992 a$. Biosynthesis of white lupin isoflavonoids from $\left[\mathrm{U}^{-14} \mathrm{C}\right] \mathrm{L}-$ phenylalanine and their release into the culture medium. Plant Physiol. 100: 76-79.

Gagnon, H., Tahara, S., Bleichert, E., and Ibrahim, R.K. $1992 b$. Separation of aglycones, glucosides and prenylated isoflavones by high-performance liquid chromatography. J. Chromatogr. 606: $255-259$.

Gagnon, H., Grandmaison, J., and Ibrahim, R.K. 1995. Phytochemical and immunocytochemical evidence for the accumulation of 2'-hydroxylupalbigenin in lupin nodules and bacteroids. Mol. Plant-Microbe Interact. 8: 131-137.

Gang, D.R., Lavid, N., Zubieta, C., Che, F., Beuerle, T., Lewinsohn, E., Noel, J.P., and Pichersky, E. 2002. Characterization of phenylpropene $O$-methyltransferases from sweet basil: facile change of substrate specificity and convergent evolution within a plant $O$-methyltransferase family. Plant Cell, 14: 505519.

Gauthier, A., Gulick, P.J., and Ibrahim, R.K. 1996. cDNA cloning and characterization of a $3^{\prime} / 5^{\prime}-O$-methyltransferase for a partially methylated flavonol from Chrysosplenium americanum. Plant Mol. Biol. 36: 1163-1169.

Gauthier, A., Gulick, P.J., and Ibrahim, R.K. 1998. Characterization of two cDNA clones which encode $O$-methyltransferases for the methylation of boh flavonoid and phenylpropanoid compounds. Arch. Biochem. Biophys. 351: 243-249.
Grandmaison, J., and Ibrahim, R.K. 1995. Ultrastructural localization of a diprenylated isoflavone in Rhizobium lupini - Lupinus albus symbiotic association. J. Exp. Bot. 46: 231-237.

Hallard, D., Bleichert, E., Gagnon, HY., Tahara, S., and Ibrahim, R.K. 1992. Production and release of isoflavonoids in lupin cell cultures. Z. Naturforsch. 47c: 346-352.

Hannoufa, A., Varin, L., and Ibrahim, R.K. 1991. Spatial distribution of flavonoid conjugates and their enzymes in Flaveria bidentis. Plant Physiol. 97: 259-263.

Hannoufa A., Brown, R.H., and Ibrahim, R.K. 1994. Variations in flavonoid sulfate patterns in relation to photosynthetic types of five Flaveria species. Phytochemistry, 36: 353-356.

Hollman, P.C., and Katan, M.B. 1998. Bioavailability and health effects of dietary flavonols in man. Arch. Toxicol. 20: 237-248.

Holton, T.A., and Cornish, E.C. 1995. Genetics and biochemistry of anthocyanin biosynthesis. Plant Cell, 7: 1071-1083.

Huang, T.-S., Anzellotti, D., Dédaldéchamp, F., and Ibrahim, R.K. 2004. Partial purification, kinetin analysis and amino acid sequence information of a flavonol 3-O-methyltransferase from Serratula tinctoria. Plant Physiol. 134: 1366-1376.

Ibrahim, R.K. 1964. Biosynthesis of hydroxybenzoic acids in plants. Biochem. Physiol. Pflanzen, 154: 481-489.

Ibrahim, R.K. 1977. Glucosylation of lignin precursors by UDPglucose:coniferyl alcohol glucosyltransferase in higher plants. Z. Pflanzenphysiol. 85: 253-262.

Ibrahim, R.K. 1990. Immunocytochemical localization of plant secondary metabolites and the enzymes involved in their biosynthesis. Phytochem. Anal. 1: 49-59.

Ibrahim, R.K. 1992. Immunolocalization of flavonoid conjugates and their enzymes. In Phenolic metabolism in plants. Edited by H. Stafford and R.K. Ibrahim. Plenum Press, New York. pp. 2561.

Ibrahim, R.K. 1997. Plant $O$-methyltransferase signatures. Trends Plant Sci. 2: 249-250.

Ibrahim, R.K., and Anzellotti, D. 2003. The enzymatic basis of flavonoid biodiversity. In Integrative phytochemistry: from ethnobotany to molecular ecology. Edited by J.T. Romeo. Pergamon, Amsterdam. pp. 1-36.

Ibrahim, R.K., and Grisebach, H. 1976. Partial purification and properties of UDP-glucose:coniferyl alcohol glucosyltransferase from Paul's scarlet rose cell suspension cultures. Arch. Biochem. Biophys. 176: 700-708.

Ibrahim, R.K., and Muzac, I. 2000. The methyltransferase gene superfamily: a tree with multiple branches. In Evolution of metabolic pathways. Edited by J.T. Romeo, R.K. Ibrahim, L. Varin, and V. De Luca. Pergamon Press, Amsterdam. pp. 349-384.

Ibrahim, R.K., and Towers, G.H.N. 1959. Conversion of salicylic acid to gentisic acid and $o$-pyrocatechuic acid, all labeled with ${ }^{14} \mathrm{C}$, in higher plant. Nature (London), 184: 1803-1804.

Ibrahim, R.K., and Towers, G.H.N. 1960a. The identification, by chromatography, of plant phenolic acids. Arch. Biochem. Biophys. 87: 125-128.

Ibrahim, R.K., and Towers, G.H.N. 1960b. Studies of hydrangenol in Hydrangea macrophylla. I. Isolation, identification and biosynthesis from $\left[{ }^{14} \mathrm{C}\right]$ labeled compounds. Can. J. Biochem. Physiol. 38: 627-634.

Ibrahim, R.K., and Towers, G.H.N. 1961. Formation of labeled sugars from $\left[{ }^{14} \mathrm{C}\right] \mathrm{L}$-tyrosine in some higher plants. Can. J. Biochem. Physiol. 39: 873-880.

Ibrahim, R.K., and Towers, G.H.N. 1962. Studies of hydrangenol in Hydrangea macrophylla. II. Biosynthesis of hydrangenol from $\left[{ }^{14} \mathrm{C}\right]$ labeled compounds. Can. J. Biochem. Physiol. 40: 449-453. 
Ibrahim, R.K., and Varin, L. 1993. Flavonoid enzymology. In Methods in plant biochemistry. Vol 9. Edited by P.J. Lea. Academic Press, London. pp. 99-131.

Ibrahim, R.K., Bohm, B.A., and Towers, G.H.N. 1961. The partial elucidation of the structure of a new coumarin from Hydrangea macrophylla. Can. J. Biochem. Physiol. 39: 1389-1395.

Ibrahim, R.K., Towers, G.H.N., and Gibbs, D.R. 1962. Syringic and sinapic acids as indicators of differences between major groups of vascular plants. J. Linn. Soc. Lond. Bot. 58: 223-230.

Ibrahim, R.K., De Luca, V., Khouri, H., Latchinian, L., Brisson, L., and Charest, J.-P. 1987. Enzymology and compartmentation of polymethylated flavonol glucosides in Chrysosplenium americanum. Phyochemistry, 26: 1237-1245.

Ibrahim, R.K., Chavadej, S., and De Luca, V. 1994. Engineering altered glucosinolate biosynthesis by two alternate strategies. In Genetic engineering of plant secondary metabolism. Edited by B.E. Ellis, G.W. Kuroki, and H.E. Stafford. Plenum Press, New York. pp. 125-152.

Ibrahim, R.K., Bruneau, A., and Bantignies, B. 1998. Plant $O$ methyltransferases: molecular analysis, common signature and classification. Plant Mol. Biol. 36: 1-10.

Jay, M., De Luca, V., and Ibrahim, R.K. 1982. Meta-Methylation of rings A (8-) and B (3'-) is catalyzed by two distinct $O$ methyltransferases in Lotus corniculatus. Z. Naturforsch. 38: 413-417.

Jay, M., De Luca, V., and Ibrahim, R.K. 1985. Purification, properties and kinetic mechanism of flavonol 8-O-methyltransferase from Lotus corniculatus. Eur. J. Biochem. 153: 321-325.

Khouri, H.E., and Ibrahim, R.K. 1984. Kinetic mechanism of a flavonol ring-B $O$-glucosyltransferase from Chrysosplenium americanum. Eur. J. Biochem. 142: 559-564.

Khouri, H.E., and Ibrahim, R.K. 1987. Resolution of five positionspecific $O$-methyltransferases by fast-protein liquid chromatofocusing. J. Chromatogr. 407: 291-297.

Khouri, H.E., Ishikura, N., and Ibrahim, R.K. 1986. FPLC purification and some properties of a partially methylated flavonol glucoside 2'-15'-O-methyltransferase from Chrysosplenium americanum. Phytochemistry, 25: 2475-2479.

Khouri, H.E., De Luca, V., and Ibrahim, R.K. 1988a. Enzymatic synthesis of polymethylated flavonols in Chrysosplenium americanum. III. Purification and kinetic analysis of $S$-sdenosylL-methionine:3-methylquercetin 7-O-methyltransferase. Arch. Biochem. Biophys. 265: 1-7.

Khouri, H.E., Tahara, S., and Ibrahim, R.K. 1988b. Partial purification, characterization and kinetic analysis of isoflavone 5-Omethyltransferase from yellow lupin roots. Arch. Biochem. Biophys. 262: 592-598.

Kornblatt, J., Muzac, I., Lim, Y., Ahn, J.H., and Ibrahim, R.K. 2004. Role of Ser286 in cosubstrate binding and catalysis of a flavonol $O$-methyltransferase. Biochem. Cell Biol. 82: 531-537.

Kurowska, E.M., and Manthey, J.A. 2004. Hypolipidemic effects and absorption of citrus polymethoxylated flavones in hamsters with diet-induced hyperchloesterolemia. J. Agric. Food Chem. 52: 2879-2886.

Laflamme, P., Khouri, H.E., Gulick, P.J., and Ibrahim, R.K. 1993. Enzymatic prenylation of isoflavones in white lupin. Phytochemistry, 34: 147-151.

Lam, K., Dayanandan, S., and Ibrahim, R.K. 2004. Phylogenomic analysis of plant $O$-methyltransferases. In Proceedings of the XXII International Conference on Polyphenols, Helsinki, Finland, 25-28 August 2004. Edited by A. Hoikkala and O. Soidinsalo. University of Helsinki, Helsinki. pp. 497-498.

Lamoureux, S., Vacha, W., and Ibrahim, R.K. 1986. Localization of partially methylated flavonol glucosides in Chrysosplenium americanum. I. Preparation and some properties of an antitrimethylflavonol glucoside antibody. Plant Sci. 44: 169-173.

Latchinian, L., and Ibrahim, R.K. 1989. Characterization of a monoclonal antibody specific to a flavonol ring-B $O$ glucosyltransferase. Biochem. Cell Biol. 67: 210-213.

Latchinian, L., and Ibrahim, R.K. 1991. Flavonol ring-B Oglucosyltransferase: purification, production of polyclonal antibodies and immunolocalization. Arch. Biochem. Biophys. 289: 230-236.

Latchinian, L., Khouri, H.E., and Ibrahim, R.K. 1987. Fast protein affinity chromatography of two flavonol $O$-glucosyltransferases. J. Chromatogr. 388: 235-242.

Macheix, J.-J., and Ibrahim, R.K. 1984. The $O$-methyltransferase system of apple fruit cell suspension culture. Biochem. Physiol. Pflanzen. 179: 659-664.

Manthey, J.A., Guthrie, N., and Grohmann, K. 2001. Biological properties of citrus flavonoids pertaining to cancer and inflammation. Curr. Med. Chem. 8: 135-153.

Marchand, L., Charest, P.-M., and Ibrahim, R.K. 1987. Localization of methylated flavonol glucosides in Chrsosplenium americanum. III. Immunogold labeling. J. Plant Physiol. 131: 339-348.

Middleton, E., Jr., and Kandaswamy, C. 1994. The impact of plant flavonoids on mammalian biology: implications for immunity, inflammation and cancer. In The flavonoids - advances in research since 1986. Edited by J.B. Harborne. Chapman \& Hall, London. pp. 619-652.

Muzac, I., Wang, J., Anzellotti, D., Zhang, H., and Ibrahim, R.K. 2000. Functional expression of an Arabiodopsis cDNA clone encoding flavonol $3^{\prime}-O$-methyltransferase and characterization of the gene product. Arch. Biochem. Biophys. 375: 385-388.

N'Dong, C., Anzellotti, D., Ibrahim, R.K., Huner, N., and Sarhan, F. 2003. Daphnetin methylation by a novel $O$-methyltransferase is associated with cold acclimation and photosystem II excitation pressure in rye. J. Biol. Chem. 278: 6854-6861.

Piotrowski, M., Schemenewitz, A., Lopukhina, A., Müller, A., Janowitz, T., Weiler, E.W., and Oecking, C. 2004. Desulfoglucosinolate sulfotransferases from Arabidopsis thaliana catalyze the final step in the biosynthesis of the glucosinolate core structure. J. Biol. Chem. 279: 50717-50725.

Pople, J.A., and Beveridge, D. 1970. Approximate molecular orbital theory. McGraw-Hill, New York.

Rice-Evans, C.A., and Miller, N.J. 1996. Antioxidant activity of flavonoids as bioactive compounds. Biochem. Soc. Trans. 24: 790-794.

Roda, A.L., Oldham, N.J., Svatos, A., and Baldwin, I.T. 2003. Allometric analysis of the induced flavonols on the leaf surface of wild tobacco (Nicotiana attenuata). Phytochemistry, 62: $527-$ 536.

Schijlen, E.G., de Vos, C.H., van Tunen, A.J., and Bovy, A.G. 2004. Modification of flavonoid biosynthesis in crop plants. Phytochemistry, 65: 2631-2648.

Schröder, G., Wehinger, E., Lukacin, R., Wellmann, F., Seefelder, W., Schwab, W., and Schröder, J. 2004. Flavonoid methylation: a novel 4'-O-methyltransferase from Catharanthus roseus, and evidence that partially methylated flavanones are substrates of four different flavonoid dioxygenases. Phytochemistry, 65: 1085-1094.

Schubert, H.L., Blumenthal, R.M., and Cheng, X. 2003. Many paths to methyl transfer: a chronicle of convergence. Trends Biochem. Sci. 28: 329-335.

Séguin, J., Muzac, I., and Ibrahim, R.K. 1998. Purification and immunological characterization of a recombinant trimethylflavonol 3'-O-methyltransferase. Phytochemistry, 49: 319-325. 
Stafford, H.A. 1990. Flavonoid metabolism. CRC Press, Boca Raton, Fla.

Tahara, S., and Ibrahim, R.K. 1995. Prenylated isoflavonoids: an update. Phytochemistry 38: 1073-1094.

Thresh, K., and Ibrahim, R.K. 1985. Are spinach chloroplasts involved in flavonoid $O$-methylation? Z. Naturforsch. 40c: 331335.

Tsang, Y.-F., and Ibrahim, R.K. 1979. Evidence for the existence of meta- and para-directing $O$-methyltransferases in tobacco cell cultures. Z. Naturforsch. 34c: 46-50.

VanEtten, H.D., Mansfield, J.W., Bailey, J.A., and Farmer, E.E. 1994. Two classes of plant antibiotics: phytoalexins versus "phytoanticipins". Plant Cell, 6: 1191-1192.

Varin, L. 1992. Flavonoid sulfation: Phytochemistry, enzymology and molecular biology. In Phenolic metabolism in plants. Edited by H. Stafford and R.K. Ibrahim. Plenum Press, New York. pp. 233-254.

Varin, L., and Ibrahim, R.K. 1989. Partial purification and characterization of three flavonol-specific sulfotransferases from Flaveria chloraefolia. Plant Physiol. 90: 977-981.

Varin, L., and Ibrahim, R.K. 1991. Partial purification and some properties of flavonol 7-sulfotransferase from Flaveria bidentis. Plant Physiol. 95: 1858-1863.

Varin, L., and Ibrahim, R.K. 1992. Novel flavonol 3sulfotransferase: purification, kinetic properties and partial amino acid sequence. J. Biol. Chem. 267: 1858-1863.

Varin, L., Barron, D., and Ibrahim. 1986. Identification and biosynthesis of sulfated and glucosylated flavonols in Flaveria bidentis. Z. Naturforsch. 41c: 813-819.

Varin, L., Barron, D., and Ibrahim, R.K. 1987a. Enzymatic assay of flavonoid sulfotransferase. Anal. Biochem. 161: 176-180.

Varin, L., Barron, D., and Ibrahim, R.K. 1987b. Enzymatic synthesis of sulphated flavonoids in Flaveria spp. Phytochemistry, 26: 135-138.

Varin, L., De Luca, V., Ibrahim, R.K., and Brisson, N. 1992. Moecular characterization of two plant flavonol sulfotransferases. Proc. Natl. Acad. Sci. U.S.A. 89: 1286-1290.
Vitali, A., Giardina, B., Monache, G.D., Rocca, F., Silvestrini, A., Tafi, A., and Botta, B. 2003. Chalcone dimethylallyltransferase from Morus nigra cell cultures: substrate specificity studies. FEBS Lett. 557: 33-38.

Willits, M.G., Giovanni, M., Prata, R.T.N., Kramer, C.M., De Luca, V., Steffens, J.C., and Graser, G. 2004. Biofermentation of modified flavonoids: an example of in vivo diversification of secondary metabolites. Phytochemistry, 65: 31-41.

Winkel-Shirley, B. 2001. Flavonoid biosynthesis: a colorful model for genetics, biochemistry, cell biology and biotechnology. Plant Physiol. 126: 485-493.

Yang, E.B., Zhao, Y.N., Zhang, K., and Mack, P. 1999. Daphnetin, one of the coumarin derivatives, is a protein kinase inhibitor. Biochem. Biophys. Res. Commun. 260: 682-685.

Yang, H., Ahn, J.-H., Ibrahim, R.K., Lee, S., and Lim, Y. 2004. The three-dimensional structure of Arabidopsis thaliana $O$ methyltransferase by homology-based modelling. J. Mol. Graph. Model. 23: 77-87.

Yazaki, K., Kunihisha, M., Fujisaki, T., and Sato, F. 2002. Geranyl diphosphate: 4-hydroxybenzoate geranyltransferase from Lithospermum erythrorhizon. J. Biol. Chem. 277: 6240-6246.

Zhang, H., Wang, J., and Goodman, H.M. 1997. An Arabisopsis gene encoding a putative 14-3-3-interacting protein, a caffeic acid/5-hydroxyferulic acid $O$-methyltransferase. Biochim. Biophys. Acta, 1353: 199-202.

Zhu, B.T., Enzell, E.L., and Liehr, J.G. 1994. Catechol $O$ methyltransferase-catalyzed rapid $O$-methylation of mutagenic flavonoids: metabolic inactivation as a possible reason for their lack of carcinogenicity in vivo. J. Biol. Chem. 269: 292-299.

Zubieta, C., He, X.-Z., Dixon, R.A., and Noel, J.P. 2001. Structures of two natural product methyltransferases reveal the basis for substrate specificity in plant $O$-methyltransferases. Nat. Struct. Biol. 8: 271-279.

Zubieta, C., Kota, P., Ferrer, J.L., Dixon, R.A., and Noel, J.P. 2002. Structural basis for the modulation of lignin monomer methylation by caffeic acid/5-hydroxyferulic acid 3/5-Omethyltransferase. Plant Cell, 14: 1265-1277. 